\title{
Situación actual del mercado de los principales rubros de exportación del estado de Yucatán
}

\section{Current market status of majors items of exports of the state of Yucatan}

\author{
Manuel J. Caro Encalada* \\ Samuel Alvarado Yah** \\ Carlos E. Leyva Morales*** \\ ${ }^{*}$ Coordinación del Cuerpo Académico \\ de Comercio Internacional. \\ mcencala@hotmail.com \\ **Coordinación de Tutorías \\ salvayah@uady.mx \\ ***Coordinación del Comité Asesor \\ de Investigación \\ clmoral@uady.mx \\ Profesores de la Facultad de Economía \\ de la Universidad Autónoma de Yucatán
}




\section{RESUMEN}

El objetivo del proyecto de donde se deriva este articulo fue caracterizar y determinar las tendencias de las principales variables del mercado mundial de los rubros de exportación más importantes del estado de Yucatán y detectar oportunidades a futuro de integración en el ámbito internacional. Se encontró que Yucatán ha tenido un desarrollo paulatino y sostenido en su comercio exterior a lo largo de la historia. Actualmente la diversificación industrial, la infraestructura en los puntos de salida de productos al exterior y el impulso a la oferta exportadora local de los gobiernos federal y estatal, han permitido que esta actividad arroje cifras crecientes y positivas, entre éstas: la tendencia creciente en el comportamiento del valor total de las exportaciones de 2002 a 2006; la fuerte participación en el valor total de las exportaciones del estado de los subsectores textil y de la confección, y de joyería; y el dinamismo exportador mostrado por los subsectores de muebles, agrícola, joyero, y de maquinarias y equipo industrial, revitalizando buena parte de la economía yucateca y generando importantes flujos de divisas, principalmente de los Estados Unidos.

Palabras clave: Mercado, exportaciones, Yucatán Clasificación JEL: F14

\section{ABSTRACT}

The objective of the project where this article is derived was to characterize and determine trends in the main world market variables of the most important Yucatán's export items and identify opportunities for future integration into the international arena. Found that Yucatan has had a gradual and sustained development on foreign trade along the history. Currently the industrial diversification, available infrastructure in abroad products exit points and the actions to boost local exporter from federal and State Governments, have enabled this activity to evolve throwing growing and positive figures, between this: the increasing behavior of the total value of exports from 2002 to 2006; strong participation in the total value of exports of the textiles and clothing, and jewelry subsectors; and dynamism on exports shown by furniture, agricultural, jeweler and that of machinery and industrial equipment subsectors, revitalizing much of yucatecan economics and generating significant flows of currencies, primarily the United States of America.

Keywords: Market, exports, Yucatán JEL Clasification: F14

Revista de Economía, vol. XXVII, núm. 74, primer semestre de 2010. 


\section{Antecedentes}

En el estado de Yucatán se ha tenido un desarrollo paulatino del comercio exterior. Las relaciones comerciales con el exterior se han realizado en la entidad (región) desde la época prehispánica; como ejemplo se tiene al pueblo maya cuyo comercio llegó a su verdadero apogeo a través del establecimiento de puertos de intercambio y de grandes mercados de transacciones a gran escala, la compra de esclavos, la realización de préstamos y también por la consolidación de las grandes rutas marítimas alrededor de la península de Yucatán. Los comerciantes de ese entonces se asociaron a la guerra para penetrar, junto con los ejércitos, en los nuevos territorios susceptibles de ser integrados a las redes comerciales (Escalante Perera, 1988).

Los comerciantes de la Península de Yucatán en esa época llevaban mantas, plumas de aves y otras mercancías a Honduras y volvían con cacao, mientras que a México-Tenochtitlán exportaban algodón, miel y sal (extraído del litoral norte de Yucatán y de la Isla Mujeres), además del cacao obtenido en Honduras y en Tabasco. Según la Relación de Motul, informe presentado por el encomendero de ese lugar al monarca español Felipe II, se dice que este comercio era tan activo que los mercaderes de Yucatán tenían representantes en Honduras para que cuidaran de sus intereses. Hubo relaciones similares con lugares tan remotos como lo que hoy es Colombia y Panamá.

Desde mediados del siglo XIX el sector comercio ha sido el más desarrollado en la península de Yucatán. El aislamiento de la península con el resto de la República, así como la producción en el estado de Yucatán de la mayoría de los satisfactores que requería para el consumo interno, propició el desarrollo de un activo comercio interior que generalmente era practicado por extranjeros radicados en el medio. No obstante el aislamiento citado, desde aquellas épocas se sostuvieron nexos comerciales con el resto del país y países extranjeros, exportando productos tales como cereales, pieles, madera, sal, azúcar o henequén; este último, producto cuya producción llegó a constituirse en la base de la economía estatal. (Mena Bates, 1985.)

Tres puertos, Sisal, Campeche y el Carmen y uno de cabotaje, Bacalar, servían al comercio yucateco en sus importaciones y exportaciones de 
mercancías. El comercio por Sisal se desarrollaba mayormente con La Habana, con participación de los comerciantes de Mérida. Por Campeche, los importadores y exportadores del lugar comerciaban principalmente con puertos del Golfo y con puertos europeos para donde se enviaba el palo de tinte, su producto más importante. El tráfico exterior se hacía con los puertos de La Habana, Belice, Nueva Orleáns, Nueva York, Boston y Malibú en los Estados Unidos, y con Liverpool, Falmouth, Bremen, Hamburgo, Amberes, Havre, Marsella y Burdeos en Europa (Escalante Perera, 1988).

$\mathrm{Al}$ prohibir Iturbide en 1822 el tráfico con España y sus colonias, entre las que Cuba quedaba incluida, los comerciantes de Mérida se rehusaron a poner en vigor esa medida. Fue natural que esa medida trajera consigo graves trastornos para Yucatán, ya que por ello se perdió el mercado de pieles, sebo y tasajo, que eran los principales renglones de exportación yucateca en ese entonces siendo desplazados por productos similares de Buenos Aires, Argentina (Pasos Pérez 1979).

Las principales mercancías exportadas al extranjero en la primera mitad del siglo XIX fueron palo de tinte, extracto de palo de tinte, maderas de construcción, jarcias, sogas e hilo de henequén, fibra de henequén, "atado en cadejos", costales, ${ }^{1}$ cueros de ganado vacuno y de venado, sebo, tabaco, sombreros, jabón, entre otros (Pasos Pérez, 1979).

Es en la segunda mitad del siglo pasado cuando comienza el henequén a ocupar el primer lugar entre las exportaciones de Yucatán, ${ }^{2}$ el henequén en rama fue el principal producto de exportación. Ya desde 1835 el henequén en rama tenía en los Estados Unidos cierta demanda entre las cordelerías para la fabricación de jarcias y cordeles y competía en calidad y precio con el cáñamo de Rusia. A partir de esta fibra muchos de los productos exportados continuaban siendo objeto de comercio hasta la octava década del siglo XIX. Así, se tiene que:

\footnotetext{
${ }^{1}$ En las primeras décadas del siglo XIX las manufacturas y en especial costales de henequén era lo que se enviaba a Cuba para envasar carbón y para otros usos.

${ }^{2}$ La primera estadística de exportación de henequén y de productos de esta fibra de que se tiene noticia corresponde al año de 1802.
} 


\begin{tabular}{|c|l|}
\hline Para La Habana: & $\begin{array}{l}\text { salían almidón, carne salada, polvillo de cas- } \\
\text { carilla (de huevo) y de concha, sombreros de } \\
\text { paja, añil, hamacas, manteca de cerdo, sabuca- } \\
\text { nes, bateas de madera, esponjas, etcétera. }\end{array}$ \\
\hline Para Belice: & $\begin{array}{l}\text { Carne salada, almidón, piedras de moler, cue- } \\
\text { ros de venado. }\end{array}$ \\
\hline Para Nueva York: & $\begin{array}{l}\text { azúcar, cereales, miel de abeja, piel de venado, } \\
\text { cuero de res al pelo, chicle, etcétera. }\end{array}$ \\
\hline Para Nueva Orleáns: & $\begin{array}{l}\text { Sombreros de paja, cigarros de papel y de hoja } \\
\text { de maíz, hilo de henequén, costales y sabuca- } \\
\text { nes. }\end{array}$ \\
\hline Para Europa: & $\begin{array}{l}\text { se exportaba, palo de tinte, cuero de res al pelo, } \\
\text { etcétera. }\end{array}$ \\
\hline $\begin{array}{l}\text { Para Veracruz y } \\
\text { otros puertos del }\end{array}$ & $\begin{array}{l}\text { salían de Sisal y luego de Progreso, sacos o } \\
\text { costales de henequén, jarcias, sogas e hilos de } \\
\text { varias clases de henequén, almidón, jabón, ve- } \\
\text { las de sebo, baúles, hamacas, puros labrados, } \\
\text { cigarrillos, pulpa de tamarindo, guitarras, cal- } \\
\text { zado, sebo, manteca de cerdo, cestos y canas- } \\
\text { tos de bejuco, peine de hueso y de madera (o } \\
\text { palos como eran llamados), bastidores, colchas } \\
\text { cameras (para camas) y catreras (para catres) } \\
\text { botones de hueso y, en volumen importante, } \\
\text { sal marina (Escalante Perera, 1988) }\end{array}$ \\
\hline
\end{tabular}

Conforme llegaba a sus postrimerías el siglo XIX muchos de los productos de Yucatán dejaron de ser exportados al dar preferencia a la fibra de henequén. Los otros artículos que conformaron en ese entonces los productos exportados fueron: 


\begin{tabular}{|l|l|}
\hline PRODUCTO & DESTINO \\
\hline Azúcar & Nueva York y Londres \\
\hline Almidón, sal a granel, carne salada & Habana y Belice \\
\hline Cuero de res & Habana y Nueva York \\
\hline $\begin{array}{l}\text { Polvillo de cascarilla, frijoles, maíz, } \\
\text { mirahuano, vaguetas, yeso }\end{array}$ & Habana \\
\hline $\begin{array}{l}\text { Calzado, tenates de bejuco, piedras de } \\
\text { moler, tabacos (puros). }\end{array}$ & Belice \\
\hline $\begin{array}{l}\text { Hule, libros impresos, pieles de venado, } \\
\text { cerdos, conchas, caucho. }\end{array}$ & Nueva York \\
\hline Palo de tinte & Nueva York y Hamburgo \\
\hline Sombreros de paja & $\begin{array}{l}\text { Habana, Belice y Nueva } \\
\text { Orleáns }\end{array}$ \\
\hline
\end{tabular}

El henequén fue el elemento rector de la configuración regional de $\mathrm{Yu}$ catán y el eje de acumulación de capital durante más de un siglo (18871990). Esta monoproducción definió una región homogénea relativamente estable, que hacia 1970 concentraba la actividad económica y al $68.1 \%$ de la población del estado, con Mérida como centro ${ }^{3}$ y el puerto de Progreso como su principal exportador de mercancías (Pasos Pérez, 1979).

Por lo tanto, se puede afirmar que durante el último cuarto del siglo XIX y principios del XX, la economía de Yucatán giró en torno del cultivo, industrialización y exportación del henequén. Su año de mayor exportación fue en 1916 (201, ooo ton). Sin embargo, a partir de 1929 la producción henequenera estatal descendió, recuperándose ligeramente durante la Segunda Guerra Mundial, y su participación en la economía estatal fue mayoritaria hasta la década de 1970, en que la contracción fue vertiginosa tanto en su fase agrícola como industrial (Eastmond, 1999).

Al paso de los años la pérdida de influencia de la producción henequenera fue total, y esta situación hizo que tomaran impulso otras actividades, tales como la industria apícola, la salinera, el procesamiento del jugo de naranja y cítricos, así como la captura de especies marinas con demanda en el mercado exterior.

${ }^{3}$ La riqueza generada por el henequén y las actividades vinculadas al mismo dio lugar al crecimiento de un centro urbano muy importante, Mérida, que llego a ser por su tamaño la quinta ciudad del país durante el Porfiriato. 
De acuerdo con los datos del periodo 1977-1981, se puede observar en el cuadro 1 el descenso que sufrieron los productos de henequén en cuanto a su participación en el total de las exportaciones del estado, pues de representar $78 \%$ en 1978 pasaron a sólo 67\% en 1981, aunque en términos generales continuaron conformando el grueso de éstas. En contraste, la miel y los productos pesqueros en ese periodo empezaron a ser de importancia para la entidad al irse incrementando sus porcentajes de participación en la exportación total realizada, de $23 \%$ y $7 \%$, respectivamente.

CUADRO 1

VALOR Y PARTICIPACIÓN PORCENTUAL DE LAS EXPORTACIONES DEL ESTADO DE YUCATÁN DE 1977 A 1981.(MILLONES DE PESOS)

\begin{tabular}{|c|c|c|c|c|c|c|c|c|c|c|}
\hline CONCEPTO & $\begin{array}{l}1977 \\
\text { Valor }\end{array}$ & $\%$ & $\begin{array}{l}1978 \\
\text { Valor }\end{array}$ & $\%$ & $\begin{array}{l}1979 \\
\text { Valor }\end{array}$ & $\%$ & $\begin{array}{l}1980 \\
\text { Valor }\end{array}$ & $\%$ & $\begin{array}{l}1981 \\
\text { Valor }\end{array}$ & $\%$ \\
\hline Total & $301 ` 622$ & 100 & $1 ` 032.7$ & 100 & $1 ` 216.0$ & 100 & $1 ` 557.3$ & 100 & $2 ` 188.8$ & 100 \\
\hline $\begin{array}{l}\text { Manufacturas de } \\
\text { Henequén }\end{array}$ & $82,404.0$ & 27.3 & 791.6 & 78 & 905.0 & 74 & 967.7 & 70 & $1,200.7$ & 67 \\
\hline Miel & $184,405.0$ & 61.1 & 138.2 & 12.5 & 240.7 & 18 & 273.0 & 13 & 660.5 & 23 \\
\hline Productos pesqueros & $34,621.0$ & 11.4 & 57.1 & 5.0 & 60.3 & 7 & 183.6 & 12 & 260 & 7 \\
\hline Sal & 192.0 & 1.0 & ND & ND & ND & ND & ND & ND & ND & ND \\
\hline Otros & -- & -- & 45.8 & 4.5 & 10.0 & 1.0 & 133.0 & 5.0 & 67.6 & 3.0 \\
\hline
\end{tabular}

Por otra parte, es importante mencionar que Yucatán desde sus orígenes comerciales también se ha caracterizado porque su comercialización externa se ha basado principalmente en materias primas, en un primer momento de las provenientes de la explotación henequenera llevada a cabo en el estado durante el siglo XIX; y posteriormente, de los de la diversificación de la producción estatal en bienes como: la miel de abeja, el jugo de naranja, las artesanías de madera, la semilla de calabaza, el pescado fresco, etc., todos también materias primas carentes de un proceso de industrialización que les permita efectuar un intercambio más favorable de mercancías con el exterior.

La diversificación de los productos del estado hacia el mercado exterior se puede ver en el cuadro que se presenta a continuación, en donde de acuerdo con los datos que se proporcionan, puede observarse que en ese periodo es cuando se registra la caída total del henequén en la participación en el comercio exterior del estado, ya que de representar $72 \%$ en el 
valor total de estas exportaciones, en 1980, pasó en 1986 a apenas 7.8\%. $\mathrm{Y}$ en contraste, en ese mismo periodo, la participación de los pescados y mariscos y de la miel de abeja en el total de las exportaciones estatales se vieron ampliamente incrementadas, alcanzando en el año de 1986 las cifras de $49.5 \%$ y $22.3 \%$, respectivamente.

CUADRO 2

EXPORTACIONES REALIZADAS EN YUCATÁN 1980,1983 Y 1986 (MILES DE DÓLARES)

\begin{tabular}{|c|c|c|c|c|c|c|}
\hline CONCEPTO & $\begin{array}{c}1980 \\
\text { VALOR }\end{array}$ & $\%$ & $\begin{array}{l}1983 \\
\text { VALOR }\end{array}$ & $\%$ & $\begin{array}{c}1986 \\
\text { VALOR }\end{array}$ & $\%$ \\
\hline Pescados y mariscos & $5,059.3$ & 11.0 & $7,975.0$ & 15.4 & $18,669.6$ & 48.5 \\
\hline Miel industrial & $3,936.0$ & 9.0 & $12,618.0$ & 24.4 & $8,597.4$ & 22.3 \\
\hline Fibra de henequén & $34,443.0$ & 72.0 & $28,558.5$ & 55.4 & $3,007.9$ & 7.8 \\
\hline Ropa & 647.0 & 3.0 & 274.0 & 0.3 & 983.2 & 2.2 \\
\hline Semilla de calabaza & 949.0 & 2.0 & 675.2 & 1.3 & 681.6 & 1.7 \\
\hline Sal común & 52.8 & 0.1 & - & - & - & - \\
\hline Manufacturas de madera & 196.1 & 1.2 & 36.7 & 0.1 & 345.5 & 1.1 \\
\hline Jugo de naranja & - & - & 590.0 & 1.1 & $2,234.6$ & 5.8 \\
\hline Otros & - & - & $1,075.6$ & 1.7 & $4,023.2$ & 7.2 \\
\hline Total & $45,383.0$ & 98.3 & $51,529.0$ & 99.7 & $49,457.0$ & 99.7 \\
\hline
\end{tabular}

De todo lo expuesto se puede concluir que el variado comportamiento histórico en el envío de productos diversos al mercado externo, marcó en la historia del comercio exterior de Yucatán una vasta experiencia y reconocimiento de los países con quienes se estableció el intercambio, lo cual se significó a su vez en el siglo pasado, por la estrategia de regionalización y diversificación productiva del estado, aprovechándose con ello todas las ventajas existentes para su comercio con el exterior.

\section{Metodología}

El objetivo del proyecto de donde se deriva el presente trabajo fue el caracterizar y determinar las tendencias de las principales variables del mercado mundial de los rubros más importantes de exportación provenientes del estado de Yucatán y detectar oportunidades a futuro de integración (en términos de competitividad) en el ámbito internacional. 
Se utilizó en el presente trabajo un diseño de comprobación de hipótesis no experimental longitudinal en su variante de análisis de tendencia (Hernández, Sampieri, R. et. al. 2003).

Las técnicas e instrumentos en las que se sustentó el estudio fueron:

1.- Revisión de literatura de las diferentes fuentes de información secundaria disponibles en la entidad (Bibliotecas, Bancomext, Sedeinco, CICY, INEGI, Sagarpa y Secretaría de Economía del estado), así como de la existente en las estadísticas de instituciones locales relacionadas con la temática (Pimexporta). Se utilizó como instrumento una bitácora de trabajo, la cual consideró los siguientes apartados de información: Antecedentes históricos, Oferta nacional, Exportación nacional, Oferta estatal, Exportaciones estatales y destino de las exportaciones estatales.

2.- La otra parte de la información se obtuvo en forma directa (trabajo de campo) por medio de entrevistas dirigidas a informantes claves (funcionarios del sector público y ejecutivos del privado relacionados con el comercio exterior de los productos de Yucatán), a quienes se les aplicó como instrumento de captura unas guías de entrevista diseñadas para tal fin.

Toda la información de campo recolectada se ordenó, clasificó y procesó por medio de una hoja de cálculo electrónica (Microsoft Excel), misma que permitió, según el caso, la estimación de los coeficientes estadísticos e indicadores matemáticos de comportamiento de interés para el estudio (tasas de cambio, medias y porcentajes); así como en la posterior relación y análisis de las variables estudiadas.

$\mathrm{El}$ análisis de resultados se fundamentó en los principios y leyes económicas relacionados con el análisis de mercado proporcionados por la teoría microeconómica, así como en los relacionados con el análisis del comercio exterior de productos, y para ello se midieron y analizaron los factores asociados al consumo, producción y comercio internacional de los rubros en estudio. 


\section{Contexto actual del Comercio Exterior de Yucatán}

Mientras más desarrollado se encuentra un país, desde el punto de vista regional, y aprovecha más cabalmente el conjunto de sus recursos humanos y naturales, resulta más firme su intercambio económico con el exterior. Con un mayor desarrollo regional interno se alcanza un mayor progreso económico general basado en los mejores rendimientos de los recursos de que se dispone. Con esto se abre la posibilidad a todas las regiones de un país de aprovechar las oportunidades que el comercio exterior les puede ofrecer.

En México, a partir de la crisis de 1982 y la caída de los precios internacionales del petróleo, la economía se transformó aceleradamente como resultado de la imposición de nuevas formas de inserción en la economía internacional. Mucho de lo anterior fue producto de las transformaciones provocadas por el llamado proceso de globalización, cuyos ejes fueron: un inédito nivel de concentración y centralización del capital, que implica su acumulación global; nuevos mecanismos de extracción de la plusvalía, que han reorganizado el proceso de trabajo; y la revolución científica-técnica, que revolucionó las fuerzas productivas. Esto ejes impulsaron en la década de los noventa la fragmentación y el cambio de escala de los procesos productivos del país, y con ello multiplicaron las condiciones económicas, sociales y políticas a escala local, regional, nacional e internacional.

En el caso de Yucatán, la ampliación del mercado regional impulsó a un buen número de industrias en esa década, al mismo tiempo que se registra una concentración y recomposición del capital con la llegada de los grandes monopolios nacionales y transnacionales, que compiten con los grupos locales por el dominio de este mercado. Como consecuencia, fuertes capitales comerciales nacionales y extranjeros desplazan a la vieja aristocracia henequenera en algunos sectores mientras que en otros, esta aristocracia se asocia, vende o es desplazada, por los grupos extrarregionales. ${ }^{4}$

\footnotetext{
${ }^{4}$ Las grandes empresas locales tradicionales pasaron a formar parte de monopolios nacionales o transnacionales, que utilizaron sus plantas peninsulares como plataforma de exportación por el Caribe y Centroamérica, el caso de la producción de cemento, el pan industrializado y la cerveza.
} 
Por otra parte, ante la mayor apertura comercial que vivió el país desde principios de los noventa, el gobierno estatal de ese entonces se tomó la tarea de estimular a las empresas locales para aprovechar las ventajas del Puerto de Altura de Progreso, así como las relaciones comerciales que estableció con los Estados Unidos de Norteamérica. Y como resultado, gran parte de las exportaciones del estado, a partir de ese momento, son realizadas por el sector maquilador, el cual se constituyó en la entidad en su mayor parte por capital extranjero, por lo que aun cuando se incrementaron las exportaciones totales de la entidad, esto no fue como consecuencia de un incremento en las ventas al exterior de los productos de las empresas yucatecas, sino del proveniente de las maquiladoras y otras empresas propiedad de capital extranjero.

Cifras al respecto indican que entre 1999 y 2005 la Inversión Extranjera Directa (IED) en el estado sumó 238.8 millones de dólares en total, que equivalen a $0.2 \%$ de la IED de todo el país. Sin embargo, esta inversión en el periodo se caracterizó en general por una tendencia decreciente ya que mientras en 2001 esta IED ascendió a los 138.3 millones de dólares; en 2002 cayó a 3.3 millones de dólares; en 2003 se recuperó ligeramente al alcanzar los 25.7 millones de dólares; pero en 2004 cayó a 16.7 millones; para finalmente en 2005 alcanzar sólo los 2.9 millones de dólares.

En términos de empresas extranjeras instaladas en el estado (Cuadro 3), datos del año 2005 indican que en total existían en ese año 626 empresas con capital extranjero operando en la entidad, de las cuales 175 representaban entidades financieras, bancarias y bursátiles, constituyendo 28 por ciento del total de la IED; seguidas en número por 112 firmas manufactureras que abarcaban $\mathbf{1 7 . 9 \%}$ de esta inversión. En el rubro de servicios, la agricultura, la ganadería, la construcción, los transportes y el comercio, así como en los hoteles y restaurantes, se concentraban sólo 256 empresas, representando $40.8 \%$ del total de la IED. 
CUADRO 3

DISTRIBUCIÓN SECTORIAL DE LA INVERSIÓN EXTRANJERA EN YUCATÁN EN 2005

\begin{tabular}{|l|c|c|}
\hline SUBSECTOR & EMPRESAS & \% DE PARTICIPACION \\
\hline Agropecuario & 9 & 1.4 \\
\hline Minería y extracción & 1 & 0.2 \\
\hline Industria manufacturera & 112 & 17.9 \\
\hline Electricidad y agua & 3 & 0.5 \\
\hline Construcción & 7 & 1.1 \\
\hline Comercio & 58 & 9.3 \\
\hline Transporte y comunicación & 5 & 0.8 \\
\hline Servicios financieros & 175 & 28.0 \\
\hline Otros servicios & $\mathbf{2 5 6}$ & 40.8 \\
\hline Total & $\mathbf{6 2 6}$ & $\mathbf{1 0 0 . 0}$ \\
\hline Fuente: SEDEINCO y Secretaría de Economía. 2006. \\
\hline
\end{tabular}

De acuerdo con el país de procedencia de las empresas, las estadounidenses encabezaban en ese año la lista con 443 empresas instaladas en la entidad y un porcentaje de participación de 70.8\%, siguiéndoles en importancia las canadienses, con 38 y participación de 6.1\%; las empresas italianas con 21, siendo su participación de 3.4\%; españolas con 16 y 2.6\% de participación; las empresas inglesas con 13 y 2.1\%; las empresas chinas con 13 y 1.9\% de participación; las francesas con 12, siendo su participación de 1.9\%; cubanas con 8 empresas y 1.3\% de participación; las Islas Vírgenes con 8 empresas y 1.3\% de participación; y las alemanas con 6 y una participación de 1.0\%.

Por lo anteriormente señalado, se deduce que la concentración de la Inversión Extranjera Directa en Yucatán se evidencia en los orígenes de procedencia de los capitales que las conforman, que en más de $71 \%$ provienen de un solo país, los Estados Unidos de Norteamérica, nación que en la entidad está presente en 443 negocios y al que se le destina la mayoría de las exportaciones de la industria maquiladora local; en tanto que de manera sectorial, la concentración se da en los servicios. Gran parte de estas empresas de capital extranjero tienen la función principal de transformar y maquilar materias primas en productos que una vez finalizados son enviados a su empresa central de origen para su comercialización en el mundo. 
Es importante señalar que, a diferencia de la etapa de evolución de las exportaciones de fibra de henequén y su derivados, en donde los insumos eran originarios de la región pues el proceso productivo agrícola e industrial tenía como fuente única la planta del agave, hoy día, en el caso de la industria maquiladora de exportación, los insumos productivos son importados directamente por las propias fábricas de sus casas matrices, por tanto, es poco representativo el componente local en el producto final exportable (Vela Sosa 2005).

Por otra parte, dado que la industria maquiladora, agente más dinámico de las exportaciones estatales, hace uso intensivo de fuerza de trabajo no calificada y sus procesos productivos no se caracterizan por incluir tecnología de punta, los bienes exportados no constituyen una oferta competitiva en términos de conocimiento innovador como lo exige el comercio global (Vela Sosa 2005). No obstante lo anterior, la presencia de las maquiladoras inyectó dinamismo al sector manufacturero del estado, fuertemente afectado en las décadas de los 70 y 80 por la decadencia en la industria de fibras duras (henequén), ofreciendo al estado nuevas expectativas para el desarrollo industrial y laboral. Ejemplo a este respecto lo constituye el subsector textil y del vestido (parte esencial en la economía del estado de Yucatán, ya que ha sido clave en su desarrollo económico), donde se dio una generación masiva de empleos con la llegada de las maquiladoras en la década de los $90 .^{5}$

En lo que respecta a las industrias locales, el estrechamiento de las relaciones del estado con el exterior ha influido para que la demanda de productos yucatecos ${ }^{6}$ sea cada vez mayor en la actualidad, lo que ha dado como consecuencia que se produzcan avances importantes en el sector industrial, operándose por consiguiente una diversificación en los productos que se elaboran en la entidad, entre éstos destacan la miel industrializada, el jugo de naranja, la carne de cerdo en cortes especializados,

\footnotetext{
${ }^{5}$ La industria manufacturera alcanzó su máxima generación de empleos en el estado en el año 2000 , debido a la importante dinámica nacional que se generó como resultado de la última década del boom económico en los Estados Unidos de Norteamérica.

${ }^{6}$ Los productos regionales son parte de nuestra vasta y antigua cultura y las ricas tradiciones. Quienes las conocen y valoran son fieles consumidores y defensores de los mismos. No se olvide que estos productos originales y únicos en el mundo constituyen elementos representativos de nuestro Estado.
} 
los productos pétreos, el cemento, las cuerdas de henequén, entre otros. A lo anterior en mucho contribuye la ubicación geográfica de Yucatán, situada en el centro del Golfo de México, punto importante entre norte, centro y América del Sur, la cual hace que el estado sea una magnífica plataforma para el comercio internacional.

Los productos yucatecos que se comercializan en el mercado internacional, paulatinamente han venido ganando mercados, a tal grado que hoy en día llegan a más de 70 países del mundo, aunque de manera aún poca diversificada; ${ }^{7}$ y su creciente presencia ha permitido al estado obtener divisas importantes provenientes de sus operaciones comerciales. Datos de la Secretaría de Desarrollo Industrial y Comercial del estado (Sedeinco, 2006) confirman la cada vez mayor aceptación de los productos locales en el exterior en países como Estados Unidos, Irlanda, Macao, Islas Caimán, Canadá, Alemania, Japón, Hong Kong, España, Cuba, Chile y Guatemala. Y que aun cuando aproximadamente $80 \%$ de las exportaciones tienen como destino final los Estados Unidos, los productos yucatecos poco a poco están encontrando otros nuevos mercados en el exterior, especialmente por el valor agregado incorporado en ellos, principalmente en los productos del ramo textil y confección, joyería, pesca, máquinas y equipos industriales, agrícolas, pecuarios, medico, quirúrgico, óptico, fotografía, muebles, alimentos procesados y bebidas.

En cuanto a los puntos de salida de los productos exportados por $\mathrm{Yu}-$ catán, éstos son básicamente dos. El puerto de Progreso es el primero, el cual es un eficaz promotor del desarrollo del sureste mexicano en los mercados internacionales, al facilitar el enlace entre el transporte marítimo y terrestre en el tráfico de mercancías y pasajeros, y convirtiéndose con ello en uno de los principales detonadores de esta zona. Este puerto de altura actualmente tiene conexiones con los puertos del Golfo de México, la costa Este de los Estados Unidos, el Caribe, Sudamérica y recientemente Europa, lo que mejora sus expectativas. Con 10 posiciones de atraque, cuatro terminales especializadas, una de carga general y un almacén refrigerado,

\footnotetext{
${ }^{7}$ En décadas recientes, la importancia y participación en la comercialización de los productos yucatecos en el contexto exterior ha recaído principalmente en los productos agropecuarios y entre sus principales productos se pueden destacar: el henequén, la miel, el jugo de naranja, la carne de cerdo, el pescado y los moluscos.
} 
este puerto cuenta con la infraestructura suficiente para despuntar en el tráfico marítimo internacional.

Por el puerto de altura de Progreso llegan y salen mercancías. Las principales que salen son: mercancías del ramo textil y confección, muebles, pescados y mariscos, miel y productos agroindustriales (en contenedores); cemento, henequén, varilla y madera (carga general); harina, aceite y grasas de origen animal, manufacturas de piedra, e instrumentos y aparatos de óptica. En tanto que las mercancías que entran son: soya, sorgo, maíz y trigo (granel agrícola), coke y sal (granel mineral) y gasolina, diesel y turbosina (hidrocarburos).

Las exportaciones por puerto Progreso han aumentado con los envíos de productos agrícolas, de la maquila y de la industria mueblera a Estados Unidos y el Caribe; de hecho ha habido ocasiones en que se han registrado más contenedores de exportación que de importación. ${ }^{8}$ Cifras oficiales al respecto indican que en lo que se refiere al manejo de contenedores, la Sedeinco destacó un incremento de $150 \%$ en el movimiento de contenedores por hora entre los años 2000 y 2006 , al pasar de $18 \%$ por hora de su capacidad total en el año 2000, a $45 \%$ por hora en el año 2006, de tal forma que la capacidad actual de operaciones es de 300 mil contenedores al año en la nueva Terminal remota de este puerto.

En tanto el segundo punto de salida lo constituye el transporte aéreo vía el Aeropuerto internacional de la ciudad de Mérida, el cual responde a la rápida y eficiente entrega de mercancías y productos comerciales, y a la variedad de opciones en costo, servicio y horarios para transporte que el actual mundo globalizado exige. El transporte aéreo tiene características diferentes a las de los otros medios, prestándose más a los productos de alto valor, de poco volumen o altamente perecederos, destacando en Yucatán las exportaciones de pescado y mariscos, seguido por las de productos terminados de maquiladoras como los textiles, la joyería y los de aparatos de ortodoncia. Desde el año 2000, el aeropuerto de Mérida contiene un almacén para el manejo de joyería, además de que es el aeropuerto más importante de la empresa Grupo Aeroportuario del Sureste SA de CV (Asur).

\footnotetext{
${ }^{8} \mathrm{El}$ movimiento de carga en materia de comercio exterior en este puerto refleja que los productos yucatecos se colocan en mayor medida en los mercados internacionales.
} 


\section{Valor de las exportaciones de Yucatán por subsector económico}

México es un país que a lo largo de las últimas décadas ha sido orientado y organizado en sus actividades productivas y de comercio exterior alrededor de tres sistemas o conjunto de políticas en el campo económico: a) de 1950 a 1972, la economía mantuvo un sistema denominado de industrialización vía sustitución de importaciones; b) de 1971 a 1981 el sistema político, sin cambiar radicalmente las de la etapa anterior, tuvo una característica preponderante de gran empuje mediante una intensiva participación del Estado en la Economía, y c) de 1982 hasta nuestros días, el sistema o conjunto de políticas se enfocaron a la liberación económica ${ }^{9}$ orientada a la inserción de México a la economía mundial. En este tercer sistema, la actividad comercial con otros países se caracterizo por crecer en promedio anual 15.4\% (de 1995 a 2005), observándose un comportamiento heterogéneo de las exportaciones e importaciones realizadas. Así se tiene que en la crisis generalizada de 1995, cuando el tipo de cambio se disparó, las importaciones cayeron 8.7 \%. En tanto que durante 2001, el comercio exterior del país se frenó de manera brusca, dado que tanto las exportaciones como las importaciones disminuyeron, $4.6 \%$ y $3.6 \%$ respectivamente.

Bajo el escenario antes expuesto, el comercio internacional en Yucatán se caracterizó por presentar un comportamiento similar en el mismo periodo, siendo la excepción el año de 1995 cuando las importaciones estatales superaron a las exportaciones, no obstante la devaluación del peso mexicano, y que tiene su explicación en la operación e instalación de las maquiladoras en el estado.

Los principales subsectores económicos del estado que presentan el mayor valor específico en el rubro total de las exportaciones que realiza el estado, están conformados de la siguiente forma: el primero de éstos es el Textil y de Confección: en él se ubican productos como cordeles, cuerdas y artículos de cordelería, hilados y tejidos. En segundo lugar se encuentra el joyero. El tercero le corresponde a la Pesca: el cual abarca productos como el pescado, fresco y refrigerado, pulpo, jaiba, camarón y langostino.

\footnotetext{
${ }^{9}$ El Libre Comercio quiere decir justamente la abolición de gravámenes entre los países que conforman un mega-mercado y de éstos con países que forman otros bloques económicos, otros mega-mercados.
} 
El cuarto es el subsector de Máquinas y Equipos Industriales. En tanto el quinto lugar es para el Pecuario que incluye: la carne porcina, la miel natural y los bovinos en pie. El sexto es el subsector Muebles. El séptimo se refiere a Otras Industrias. El octavo es el subsector Médico-Quirúrgico, Óptico y de Fotografía: que elabora productos manufacturados aparatos ortopédicos, instrumentos y aparatos odontológicos, entre otros. El noveno es el de Alimentos Procesados y Bebidas: que comprende lo que se refiere a jugo de naranja, grasas y aceite animal y vegetal, condimentos y salsas preparadas, etc. En el décimo se tiene el subsector de Plásticos y sus Manufacturas. En decimoprimero se ubica la Agricultura: conformado por cítricos, papaya, pepino, pepinillo, sandia, limones y tomate. $Y$ en decimosegundo lugar están los minerales no Metálicos: en donde se encuentran la sal, el cemento, piedra, grava y gravilla, polvo de piedra, entre otros.

En el cuadro 4, que se presenta a continuación, se exponen las cantidades que corresponden al valor total de las exportaciones del estado durante el periodo de 1998 a 2006.

\section{CUADRO 4}

VALOR TOTAL DE LAS EXPORTACIONES DEL ESTADO

DE YUCATÁN 1998-2006 (MILLONES DE DÓLARES)

\begin{tabular}{|c|c|}
\hline AÑO & EXPORTACIONES \\
\hline 1998 & 316.0 \\
\hline 1999 & 384.0 \\
\hline 2000 & 443.0 \\
\hline 2001 & 402.0 \\
\hline 2002 & 995.7 \\
\hline 2003 & 979.6 \\
\hline 2004 & 1173.7 \\
\hline 2005 & 1242.6 \\
\hline 2006 & 1289.2 \\
\hline
\end{tabular}

Fuente: De 1998 a 2001 Sedeinco. Dirección de Comercio Internacional. Con datos de la Secretaría de Economía. De 2002 a 2006, Sedeinco con datos de la Administración General de Aduanas.

Como se puede apreciar, en los primeros años del periodo señalado, de 1998 a 2001, el valor total de las exportaciones se caracterizó por mantener un crecimiento moderado (promedio anual de 9.21\%), aunque con una tendencia decreciente en términos generales. En tanto que de 2002 a 2006, el valor total de las exportaciones del estado mostró un crecimiento más significativo (promedio anual de 35.10\%), aunque en lo general una 
vez más presentó una tendencia decreciente en su comportamiento. Así, se tiene que durante los dos primeros años del segundo lapso establecido, 2002 y 2003, el valor total de las exportaciones fue de 995.7 a $979.6 \mathrm{mi}-$ llones de dólares, una tasa de crecimiento de $-1.6 \%$ con respecto del año anterior; en tanto que en 2004 el valor total que alcanzaron estas exportaciones sumaron la cantidad de 1,173.7 millones de dólares, lo que representó un crecimiento de 19.8\% en relación con el año anterior. En 2005 la actividad exportadora del estado mantuvo una participación creciente en el valor total comercializado, aunque con una tasa bastante menor, de sólo 5.9\% en relación con 2004; y en 2006 el porcentaje de aumento del valor total de las exportaciones locales registró sólo un 3.7\% con respecto del año 2005 al alcanzar la cantidad de 1,289.2 millones de dólares.

Particularizando el análisis de estas cifras, en cuadro 5 se tiene que del valor total de las exportaciones de Yucatán en el año 2002 (995.7 millones de dólares) uno de los principales subsectores participantes fue el textil y de la confección, el cual exportó productos por valor de 597.4 millones de dólares, otros subsectores económicos que de acuerdo con su importancia generaron ingresos importantes de divisas para el estado fueron: joyería, pesca, pecuario, otras industrias, máquinas y equipos industriales y el médico-quirúrgico, óptico y fotografía. Estos subsectores en conjunto sumaron un total de 965.88 millones de dólares, en tanto los restantes participaron con solo 29.4 millones de dólares en el valor generado en 2002. Los principales países a los que se enviaron estas exportaciones fueron en ese año: Estados Unidos, Alemania, Canadá, España, Italia, y Honduras.

En el año siguiente, 2003 el monto de las exportaciones del estado destinadas al exterior sufrió una reducción por causa de factores externos (ascendió a sólo 979.6 millones de dólares). En efecto, en el trienio 20012003 se presentaron variables externas, o fuera de control de la política económica estatal, que indudablemente afectaron el entorno económico y sus resultados, entre las cuales destacan los ataques terroristas en Estados Unidos de Norteamérica y la incertidumbre en torno de la recuperación económica de ese país, los conflictos bélicos en Medio Oriente, la volatilidad en los mercados accionarios mundiales a raíz de las irregularidades contables en corporativos internacionales, la crisis económica y política por la que atravesaron algunas naciones latinoamericanas, y la dificultad de alcanzar consensos para impulsar las reformas estructurales que requería 
Situación actual del mercado de los principales rubros

\begin{tabular}{|c|c|c|c|c|c|c|c|c|c|c|c|c|c|c|c|}
\hline & $\begin{array}{l}\text { 岁察宫 } \\
\text { do }\end{array}$ & $\underset{\mathcal{Z}}{\stackrel{7}{8}}$ & $\mid \begin{array}{l}0 \\
\dot{m} \\
\dot{m}\end{array}$ & 旾 & $\stackrel{0}{\dot{m}}$ & $\tilde{m}$ & $\begin{array}{r}\vec{m} \\
\dot{m}\end{array}$ & $\stackrel{n}{\sim}$ & $\vec{i}$ & $\stackrel{-1}{-}$ & ?ִ & $\begin{array}{l}\infty \\
0 \\
0\end{array}$ & : & $\mid \begin{array}{l}0 \\
0 \\
0 \\
\end{array}$ & \\
\hline & 㟧 نِّ & $\stackrel{\vec{f}}{\vec{f}}$ & $\vec{i}$ & $\mid \begin{array}{l}n \\
\dot{m} \\
m\end{array}$ & $\begin{array}{l}6 \\
\stackrel{0}{9} \\
\rightarrow\end{array}$ & $\stackrel{m}{\rightarrow}$ & $\left.\begin{array}{l}n \\
\\
\infty\end{array}\right]$ & $\begin{array}{c}N \\
\infty \\
\sim \\
\sim\end{array}$ & $\stackrel{\circ}{i}$ & 艿 & $\underset{\substack{0 \\
\infty}}{\substack{0 \\
0}}$ & $\begin{array}{l}0 \\
\dot{\varphi} \\
\dot{m}\end{array}$ & 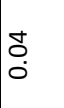 & $\hat{m}$ & \\
\hline & ๕ั้ & $\mid \begin{array}{l}n \\
0 \\
i \\
n\end{array}$ & $\mid$\begin{tabular}{c}
$n$ \\
$\vdots$ \\
\hdashline \\
$m$
\end{tabular} & 妾 & $\begin{array}{l}0 \\
\dot{f} \\
\dot{f}\end{array}$ & $\begin{array}{c}\tilde{i} \\
\dot{q} \\
\end{array}$ & 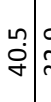 & $\begin{array}{ll}\stackrel{a}{m} \\
\dot{m}\end{array}$ & 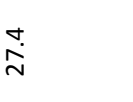 & 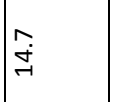 & $\stackrel{+}{\stackrel{+}{*}}$ & 吕 & $\underset{\infty}{\infty}$ & 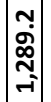 & \\
\hline : & 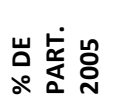 & $\begin{array}{l}\infty \\
\dot{f} \\
\dot{f}\end{array}$ & $\mid \begin{array}{l}0 \\
\infty \\
\sim\end{array}$ & in: & $\stackrel{f}{\dot{\sigma}}$ & $\underset{m}{\sim} \underset{m}{m}$ & $\stackrel{8}{3}$ & $\stackrel{\sim}{i}$ & $\vec{i}$ & $\stackrel{+}{\stackrel{\Delta}{*}}$ & i̊ & $\begin{array}{l}0 \\
0 \\
0\end{array}$ & : & ఫి & \\
\hline ヘี้ & 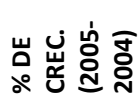 & g & $\mid \begin{array}{c}-1 \\
6\end{array}$ & $\mid \begin{array}{l}\infty \\
\uparrow \\
\uparrow\end{array}$ & $\begin{array}{l}\sim \\
\tilde{n} \\
\tilde{n}\end{array}$ & & $\left|\begin{array}{l}0 \\
\dot{6}\end{array}\right|$ & $\begin{array}{l}6 \\
\dot{\sim} \\
\vec{\sim}\end{array}$ & $\stackrel{\substack{\infty \\
\infty}}{ }$ & $\hat{\text { pin }}$ & $\stackrel{d}{\stackrel{d}{d}}$ & $\begin{array}{l}\infty \\
0 \\
- \\
-1\end{array}$ & 悹 & $\left|\begin{array}{c}\infty \\
\dot{n}\end{array}\right|$ & \\
\hline 을 & นั & 亲 & Na & 帒 & กี่ & $\begin{array}{l}\hat{o} \\
\dot{q}\end{array}$ & & $\begin{array}{c}\infty \\
\sim \\
\sim\end{array}$ & $\begin{array}{l}\infty \\
\stackrel{\infty}{\infty}\end{array}$ & 文 & $\stackrel{n}{n}$ & $\mid$ & 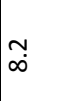 & 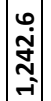 & \\
\hline 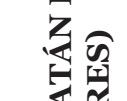 & 㟧容宫 & $\mid \begin{array}{l}m \\
\infty \\
\infty \\
\sigma\end{array}$ & $\left|\begin{array}{l}\infty \\
\infty \\
\sim\end{array}\right|$ & ตุ & 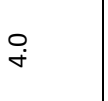 & $\begin{array}{l}0 \\
\dot{+}\end{array}$ & fils & $\stackrel{0}{i}$ & $\vec{i}$ & ㄱ. & ஒ̊̊ & ָ̃. & $\stackrel{n}{o}$ & ঃి & \\
\hline مُ & 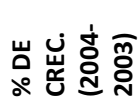 & ṫ & S̊ & 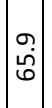 & $\begin{array}{l}\text { o. } \\
\text { in }\end{array}$ & $\stackrel{\infty}{i}$ & & 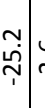 & $\stackrel{\bullet}{i}$ & ồ & $\stackrel{m}{\underset{j}{H}}$ & 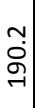 & 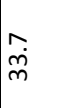 & $\mid \begin{array}{l}\infty \\
\text { aे }\end{array}$ & \\
\hline 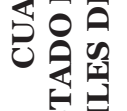 & ర్స & $\begin{array}{l}-1 \\
\overline{\hat{L}} \\
\text { in }\end{array}$ & $\begin{array}{c}\dot{D} \\
\infty \\
m \\
m\end{array}$ & : & $\begin{array}{l}m \\
\dot{\sigma} \\
\dot{\sigma}\end{array}$ & $\begin{array}{l}0 \\
\dot{q} \\
\dot{q}\end{array}$ & ণ্ & $\begin{array}{l}\mathfrak{d} \\
\stackrel{\sim}{\sim}\end{array}$ & 竎 & $\stackrel{-1}{m} \underset{\sim}{-1}$ & 㣁 & $\stackrel{\vec{m}}{\dot{m}}$ & 官 & $\mid \begin{array}{l}\hat{n} \\
\hat{n} \\
\\
-i\end{array}$ & \\
\hline 臸 & 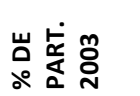 & 它 & $\begin{array}{l}0 \\
\dot{i}\end{array}$ & $\stackrel{m}{\dot{r}}$ & $\underset{\sim}{\sim}$ & $\hat{\dot{q}}$ & $\left|\begin{array}{r}0 \\
0 \\
0\end{array}\right|$ & $\underset{m}{m}=$ & $\stackrel{d}{\sim}$ & $\stackrel{-}{-}$ & $\stackrel{9}{0}$ & -1. & o. & ০ి & \\
\hline 䓀 & 㟧 & 虫 & $\begin{array}{l}0 \\
0 \\
9 \\
9\end{array}$ & רై & $\begin{array}{l}\infty \\
\dot{m} \\
\dot{m}\end{array}$ & 官 & 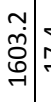 & ثे. & $\stackrel{m}{r}$ & $\underset{\sim}{\tilde{Y}}$ & - & $\stackrel{\infty}{\sigma}$ & 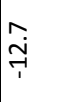 & $\mid \begin{array}{c}0 \\
-i \\
-i\end{array}$ & \\
\hline 湈 & ర్సે & 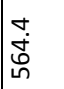 & $\begin{array}{l}\infty \\
\stackrel{\infty}{0} \\
\end{array}$ & $\stackrel{\sim}{\stackrel{\sim}{y}}$ & in & $\begin{array}{c}m \\
\dot{b} \\
q\end{array}$ & & $\stackrel{n}{i m}$ & $\begin{array}{l}\stackrel{\circ}{\sim} \\
\text { d }\end{array}$ & $\begin{array}{l}\infty \\
0 \\
0 \\
-1\end{array}$ & $\hat{\sigma}$ & 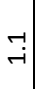 & $\mid \underset{+}{\dot{\alpha}}$ & $\left|\begin{array}{c}6 \\
\hdashline \\
\vdots \\
\vdots\end{array}\right|$ & 离 \\
\hline 齐 & 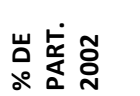 & कें & $\mid \begin{array}{l}0 \\
\infty \\
-\rightarrow\end{array}$ & in & $\stackrel{m}{i}$ & $\underset{\dot{q}}{\mid}$ & $\hat{i}$ & స̃ & $\begin{array}{l}\text { mo } \\
0 \\
0\end{array}$ & $\stackrel{\sim}{\sim}$ & $\stackrel{-}{\rightarrow}$ & $\stackrel{n}{0}$ & -1-1 & ৪্ন & $\underset{t}{2}$ \\
\hline & ర్ & 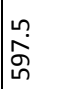 & \begin{tabular}{l}
0 \\
$\dot{0}$ \\
0 \\
\hdashline
\end{tabular} & ì & $\stackrel{m}{\tilde{m}}$ & $\begin{array}{l}0 \\
\dot{q} \\
\dot{q}\end{array}$ & & $\begin{array}{l}0 \\
\stackrel{\sim}{N}\end{array}$ & 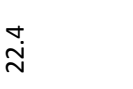 & 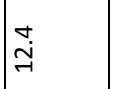 & 豙 & il & |r. & 命 & . \\
\hline & 崽 & 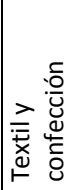 & $\mid$ & 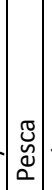 & 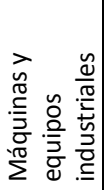 & 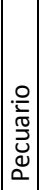 & $\mid \begin{array}{l}\frac{0}{0} \\
\frac{a}{0} \\
\frac{a}{2}\end{array}$ & 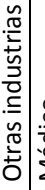 & 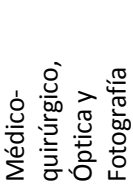 & 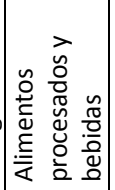 & 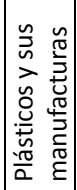 & & 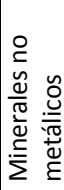 & 吾 & $\sum_{\underline{u}}^{\vec{u}}$ \\
\hline
\end{tabular}


la economía nacional. Sin embargo, fue la recesión internacional la que impactó de manera más severa en algunos sectores de actividades en los que se realiza la actividad exportadora local, como la textil, de prendas de vestir y la del cuero, actividades claves de la industria manufacturera estatal y en la generación de divisas extranjeras. Las cifras de participación que se registraron en ese año fueron: el subsector textil y confección con 564.4 millones de dólares, joyería con 205.8, pesca con 42.2 millones de dólares, pecuario 46.3 millones de dólares, máquinas y equipos industriales con 31.5 millones de dólares, otras industrias con 32.5 millones de dólares, el sector médico-quirúrgico, óptico y fotografía con 24 millones de dólares y muebles con 6.4 millones de dólares. En forma conjunta estos subsectores sumaron un total de 953.6 millones de dólares.

Las condiciones favorables en el año 2004 en el contexto económico internacional, se vieron reflejadas en el incremento en el valor de las exportaciones de la entidad provenientes de los diversos productos comercializados con otros países. Así en ese año, ante un contexto exterior en recuperación, el valor total de las divisas que procedieron de las exportaciones alcanzaron la cantidad total de 1,173.7 millones de dólares (tasa de crecimiento de $19.8 \%$, la más alta del periodo). Los principales subsectores exportadores siguieron siendo aquellos tradicionales y representativos en cuanto a participación en el valor total, siendo éstos en orden de importancia: el textil y confección, joyería, pesca, pecuario, maquinaria y equipo industrial, el médico-quirúrgico, óptico y fotografía, otras industrias y el de muebles. Las cifras que registraron cada uno fueron: el subsector textil y confección con 567.1 millones de dólares, joyería con 338.4, pesca con 70.1 millones de dólares, pecuario 47.6 millones de dólares, máquinas y equipos industriales con 47.3 millones de dólares, el sector médico-quirúrgico, óptico y fotografía con 24.7 millones de dólares, otras industrias con 24.2 millones de dólares y muebles con 20.4 millones de dólares. En forma conjunta sumaron un total de 1,362.1 millones de dólares.

En el año 2005, por su parte, se mantuvo la tendencia ascendente en el valor total de las exportaciones estatales, las cuales sumaron la cantidad de 1,242.6 millones de dólares (incremento del 5.8\%). En este año, el subsector textil y confección contribuyó con 594.9 millones de dólares, joyería con 359.2, pesca con 64.5 millones de dólares, máquinas y equipos industriales con 59.2 millones de dólares, pecuario 40.7 millones de 
dólares, muebles con 21.8 millones de dólares, otras industrias con 27.8 millones de dólares y el sector médico-quirúrgico, óptico y fotografía con 26.8 millones de dólares. En forma conjunta estos subsectores sumaron 1,194.7 millones de dólares en tanto los demás, el de alimentos procesados y bebidas, el del plástico y sus manufacturas, la agricultura y los minerales no metálicos, contribuyeron con sólo 47.9 millones de dólares.

En el año 2006, no obstante que la tendencia creciente se mantuvo en el comportamiento de este indicador, este valor sólo ascendió a la cantidad de 1,289.2 millones de dólares (tasa de crecimiento de sólo 3.7\%). En este año una vez más un reducido número de subsectores económicos fueron los que contribuyeron en la generación de esos montos totales, siendo la distribución de esta participación la siguiente: el subsector textil y confección contribuyó con 570.2 millones de dólares, joyería con 399.2, pesca con 84.1 millones de dólares, máquinas y equipos industriales con 47.6 millones de dólares, pecuario 41.2 millones de dólares, muebles con 40.5 millones de dólares, otras industrias con 32.9 millones de dólares y el sector médico-quirúrgico, óptico y fotografía con 27.4 millones de dólares. En forma conjunta estos subsectores sumaron 1,243.1 millones de dólares en tanto los demás, el de alimentos procesados y bebidas, el del plástico y sus manufacturas, la agricultura y los minerales no metálicos, contribuyeron con sólo 46.1 millones de dólares.

En lo que se refiere a la participación en el valor total exportado en 2003, los subsectores más representativos fueron: el textil y confección con una tasa de $57.6 \%$, el de la joyería con una participación de $21 \%$ en el total, el subsector pecuario con una tasa del $4.7 \%$ y el de pesca con una contribución de $4.3 \%$.

Como fue señalado previamente, las condiciones favorables del año 2004 en el contexto económico internacional se vieron reflejadas en un incremento en el valor total de lo exportado por el estado, lo cual en términos de la contribución de los subsectores económicos sólo se reflejó en forma significativa en dos de éstos, el textil y de confección con una tasa de $48.3 \%$ y el de la joyería con una participación de $\mathbf{2 8 . 8 \%}$ en el total. Sin embargo, hay que señalar que, aunque en menor grado, otros subsectores que registraron en este año mejoras en su contribución al total fueron el de la pesca con una tasa de participación de 5.9\%, y los de máquinas y equipos industriales y el pecuario, con una participación respectiva de $4 \%$ cada uno. 
Para el año 2005, los porcentajes de participación de los subsectores en el valor total de las exportaciones, como puede observarse, señalan nuevamente al subsector textil y de la confección como el principal, con 47.8\% del total, siguiéndole en importancia el joyero, el cual contribuyó con $29 \%$. Se ubican en ese año en el tercer y cuarto lugares los subsectores de la pesca, con participación de $5.1 \%$, y el de máquinas y equipos industriales, con $4.7 \%$.

En el 2006 la situación se mantuvo prácticamente igual en cuanto a la participación por subsector, siendo de nueva cuenta el textil y de confección el más importante, con una tasa de contribución de 44.2\% (esta tasa resultó menor a la de 2005, siendo la causa de esta disminución el menor número de maquiladoras instaladas en la entidad), siguiéndole en importancia el de la joyería con una participación de $31 \%$, el subsector pesca con un $6.5 \%$ y por último el de máquinas y equipos industriales con una contribución en 2006 de 3.6\%. Hay que destacar que en este año el subsector mueblero fue de los más dinámicos, registrando un aumento significativo en su participación en el valor total de las exportaciones, pasando de contribuir con $1.7 \%$ en 2005 a 3.1\% en el 2006.

\section{Dinámica de las exportaciones de Yucatán}

En este apartado se analizan los incrementos o decrementos porcentuales que presentaron los subsectores exportadores del estado en el periodo establecido. Así, se tiene que en el año 2003, los principales subsectores económicos que registraron incrementos con respecto de 2002 en su tasa de crecimiento, fueron los siguientes: muebles con una tasa de variación del $1,603.2 \%,{ }^{10}$ máquinas y equipos industriales con una variación de $34.8 \%$, otras industrias con $17.4 \%$, joyería con un crecimiento de $10.6 \%$ y por último, el de médico-quirúrgico, óptico y fotografía con una tasa de $7.3 \%$. En tanto que los que registraron tasas negativas de crecimiento fueron: pesca en primer lugar con una caída de -29.2\%, minerales no metálicos con $-12.7 \%$, el de alimentos procesados y bebidas con una disminución

\footnotetext{
${ }^{10}$ En diciembre de este año se inaugura el Parque Industrial Mueblero en el Municipio de Umán (Yucatán), único de su tipo en el país, lo cual se reflejó en la altísima tasa de crecimiento que experimentó este sector productivo.
} 
de -12.2\%, el sector plástico y sus manufacturas con un -11.6\%, el textil y confección con una disminución de $-5.5 \%$ y por último el pecuario con una tasa de variación de $-5.4 \%$.

En el año siguiente, 2004, en forma general se dio un incremento en las tasas de cambio de las exportaciones de la gran mayoría de estos subsectores económicos en relación con el año 2003, con excepción del sector de otras industrias que registró una tasa negativa de -25.2\%. Los subsectores más dinámicos en ese año fueron los siguientes: muebles con una tasa de $216.2 \%$, la agricultura con una variación de $190.2 \%$, pesca con una tasa de $65.9 \%$, joyería con un crecimiento de $64.4 \%$ y por último, el de máquinas y equipos industriales con una tasa de $50 \%$.

Para 2005 nuevamente la gran mayoría de los subsectores exportadores de Yucatán registraron tasas de crecimiento positivas, destacando el de la agricultura, con un incremento de $\mathbf{1 1 9 . 8 \%}$; el de minerales no metálicos, que abarca la sal y los materiales de construcción, con $37 \%$; el de alimentos y bebidas con $35.7 \%$; y el máquinas y equipos industriales con $25.2 \%$. Los únicos dos subsectores que en ese año registraron tasas de crecimiento negativas en la comercialización de sus productos y por ende en la generación de ingresos para la economía del estado fueron: el pesquero, que experimentó en 2005 un decremento de $-7.8 \%$ y el subsector pecuario que presento una disminución de $-14.4 \%$.

En cuanto a los subsectores con mayor presencia en el mercado extranjero en el año 2006, los más importantes por sus tasas de crecimiento del valor generado por la comercialización internacional de sus productos fueron el textil, el joyero, el pesquero, el de máquinas y equipo, el pecuario, el de muebles y la agricultura. Estos subsectores fueron los que registraron un comportamiento positivo en sus tasas, aunque a niveles menores, ubicándose en el primer lugar el subsector mueblero con un crecimiento de $85.5 \%$, seguido del de la agricultura con $36 \%$, el de la pesca con $30.2 \%$, el de otras industrias con $18.5 \%$ y el joyero con $11.1 \%$. Los subsectores que denotaron tasas negativas de crecimiento en el valor de lo que exportaron en 2006 fueron el textil con $-4.1 \%$, máquinas y equipos industriales con $-19.6 \%$, el sector de alimentos procesados y bebidas con $-17.3 \%$ y el de plásticos y sus manufacturas con $-8.4 \%$. 


\section{Comportamiento de los subsectores exportadores de Yucatán}

Desde finales del siglo XIX a inicios del actual siglo XXI, el comercio exterior de Yucatán se caracterizó por, primeramente, desarrollarse basado en productos provenientes del sector primario y, posteriormente, por los originados en el ramo maquilador. Así el sector agrícola tuvo una presencia destacada, sin competencia significativa durante un largo tramo del siglo XX, en tanto el sector maquilador es hoy día el más dinámico en la generación de bienes destinados al mercado externo, representando cerca del 50\% del total de las exportaciones que tienen su origen en Yucatán, aunque en términos de su contribución al total de las exportaciones mexicanas no representa ni 1\%. (Vela Sosa. 2005.)

Por otro lado, considerando los acontecimientos tanto externos como internos que se dieron en el desarrollo histórico del país, se pueden ubicar dos momentos en la historia de la Industria Maquiladora de Exportación en Yucatán. El primero inicia en el año de 1984, cuando la sede de las empresas extranjeras es la capital del estado, la ciudad de Mérida, y sus alrededores; en tanto el segundo arranca en 1992, con el desplazamiento de esta Industria Maquiladora a diferentes poblaciones de la entidad, reforzada con la firma del Tratado de Libre Comercio (TLC) en 1994. Cabe señalar que la firma de este tratado atrajo empresas al estado, provenientes principalmente de la inversión extranjera directa de los Estados Unidos de Norteamérica en la entidad, cuyo mercado final fueron el mismo Estados Unidos, y también, otras provenientes de otros países, que contemplaron las expectativas de ingresar al mercado norteamericano vía el nuestro.

Actualmente, las empresas grandes establecidas en el estado siguen siendo la principal fuente de las exportaciones de Yucatán, sin embargo, micros, pequeñas y medianas empresas locales ${ }^{11}$ ya están ocupando una proporción considerable en éstas; uno de cada cuatro dólares que se exportan proviene de ellas.

\footnotetext{
${ }^{11}$ Las pequeñas y medianas empresas constituyen una porción considerable de la actividad económica del estado, aproximadamente $16 \%$, pero su mercado de acción se ve limitado por falta de infraestructura, de financiamiento, o bien, por la falta de información para poder incursionar en la actividad exportadora de productos locales a otros mercados, tanto nacionales como internacionales.
} 
Las exportaciones de las empresas grandes corresponden principalmente a los subsectores textil, joyero y pecuario, mientras que las empresas medianas se concentran más a la venta al exterior de los subsectores joyero, textil, de máquinas y equipos industriales, de muebles y de productos pesqueros. En cuanto a las exportaciones de las empresas pequeñas, éstas se enfocan principalmente en los productos pesqueros, los alimentos procesados y las bebidas. En cuanto al comportamiento del valor de las exportaciones por subsector económico del estado, las principales características de cada uno fueron:

Subsector textiles y de confección. Actualmente es el principal subsector exportador de Yucatán en cuanto a valor. Entre los productos manufacturados por este subsector se encuentran principalmente trajes sastre, conjuntos, vestidos, falda-pantalón, pantalones, shorts, camisas, blusas, suéteres, telas, hilados, cuerdas y artículos de cordelería, etcétera.

En lo que respecta al comportamiento de las exportaciones de este subsector en el periodo 2002-2006, las cifras oficiales indican una disminución total de - 4.5\%, comparando el valor de las exportaciones alcanzadas en 2002 con respecto de las del año 2006, registrándose en lo general una tendencia descendente en el periodo. Entre algunas de las causas de este comportamiento se pueden señalar el cierre de maquiladoras que se registró en el estado desde el año 2002, su traslado a otros países, entre otros (Gráfica 1).

Los principales países a los que se envían las exportaciones de textiles y de confección elaborados en la entidad son: Estados Unidos, Alemania, Canadá, España, Italia, Honduras, Irlanda, Macao, Islas Caimán y Hong Kong.

Subsector joyero. Es el segundo subsector económico importante en materia de comercio exterior del estado, el cual ha sido de los más impulsados para su desarrollo y fortalecimiento por parte del gobierno.

La importancia de este subsector joyero queda demostrada en la tendencia creciente presentada en el valor de sus exportaciones, las cuales de 2002 al 2006 registraron un incremento total de 114\%, el tercero más dinámico (Gráfica 4).

Según la Sedeinco, este subsector es uno de los tres con mayor presencia en el extranjero, siendo Estados Unidos el principal destino de los artículos de joyería manufacturados en tierras yucatecas, aunque también se empieza a exportar productos de esta industria a países como Canadá e Italia. 

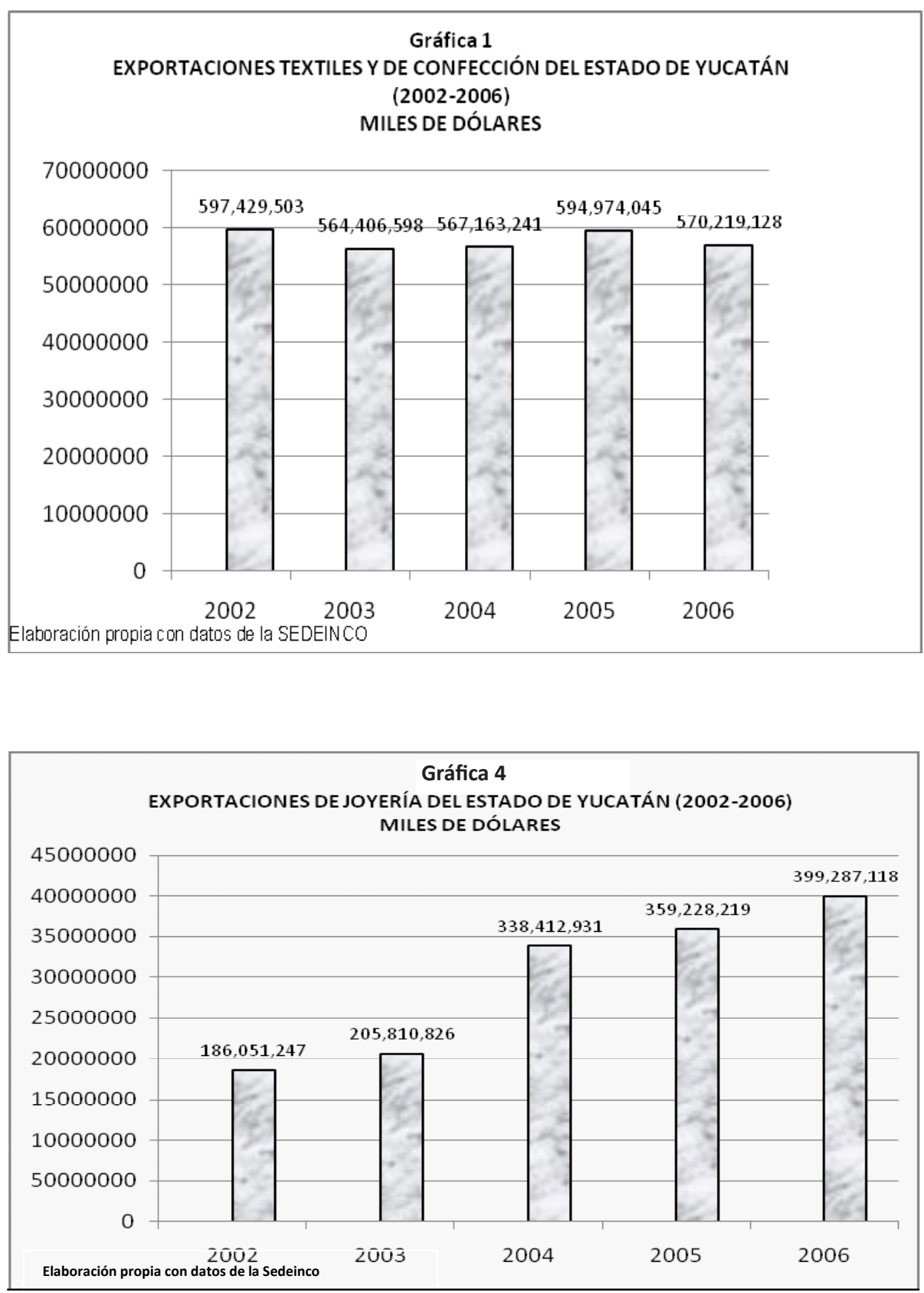
Actualmente, como consecuencia de la destreza de la mano de obra local y el perfil del estado para la inversión, este subsector ha constituido una oportunidad de crecimiento para la entidad. A lo anterior, hay que añadirle la ubicación geográfica del estado, la cual lo coloca como el punto más conveniente para comerciantes y fabricantes de estos productos de las costas del sur y este de Estados Unidos, así como del Caribe, Centroamérica y del mismo México. Asimismo, la entidad se ha convertido en importante polo de atracción para las empresas de este subsector, por la infraestructura, área con que cuenta para mover las mercancías que se producen y por la seguridad que priva en el estado.

Subsector muebles. Yucatán ha tenido desde hace muchos años gran vocación en el trabajo de maderas y tapices. A través del tiempo, esta actividad no sólo se ha desarrollado por el aumento de la demanda de muebles en los ámbitos regional y nacional, ocasionado principalmente por el crecimiento y desarrollo de las zonas hoteleras de Cancún y la Reviera Maya, sino que se ha consolidado como industria importante de exportación en la entidad. Hoy en día, el estado cuenta con empresas nacionales y extranjeras que venden sus productos tanto al mercado nacional como al extranjero, a Estados Unidos, Canadá y Europa, principalmente.

Este subsector económico es ejemplo importante en materia de comercio internacional ya que en el periodo 2002- 2006 sus exportaciones presentaron una tendencia creciente, especialmente a partir de la instalación de importantes empresas de este rubro en el estado y de la puesta en marcha del Parque Mueblero de Yucatán, siendo su crecimiento total en el periodo de los más significativos, con 10, 554.53\% (Gráfica 2).

La tecnología de vanguardia y las manos yucatecas transforman la madera de Chile, el látex de Francia, los resortes de Alemania y el poliuretano de Estados Unidos (entre otros insumos) en colchones, sofás y otros finos artículos muebleros de exportación cuya mayor parte son enviados al extranjero. Por consiguiente, se puede afirmar que la industria mueblera es otro subsector económico que se ha sumado en forma dinámica a las exportaciones del estado.

Subsector agricultura. Este es otro de los subsectores que presentaron un gran dinamismo en el crecimiento del valor de sus exportaciones, 
como puede apreciarse en la gráfica 3 a continuación, con un crecimiento total de $853.19 \%$ (el segundo más dinámico). Sin embargo, su participación en el valor exportado es muy bajo (de sólo 0.8\% en 2006).
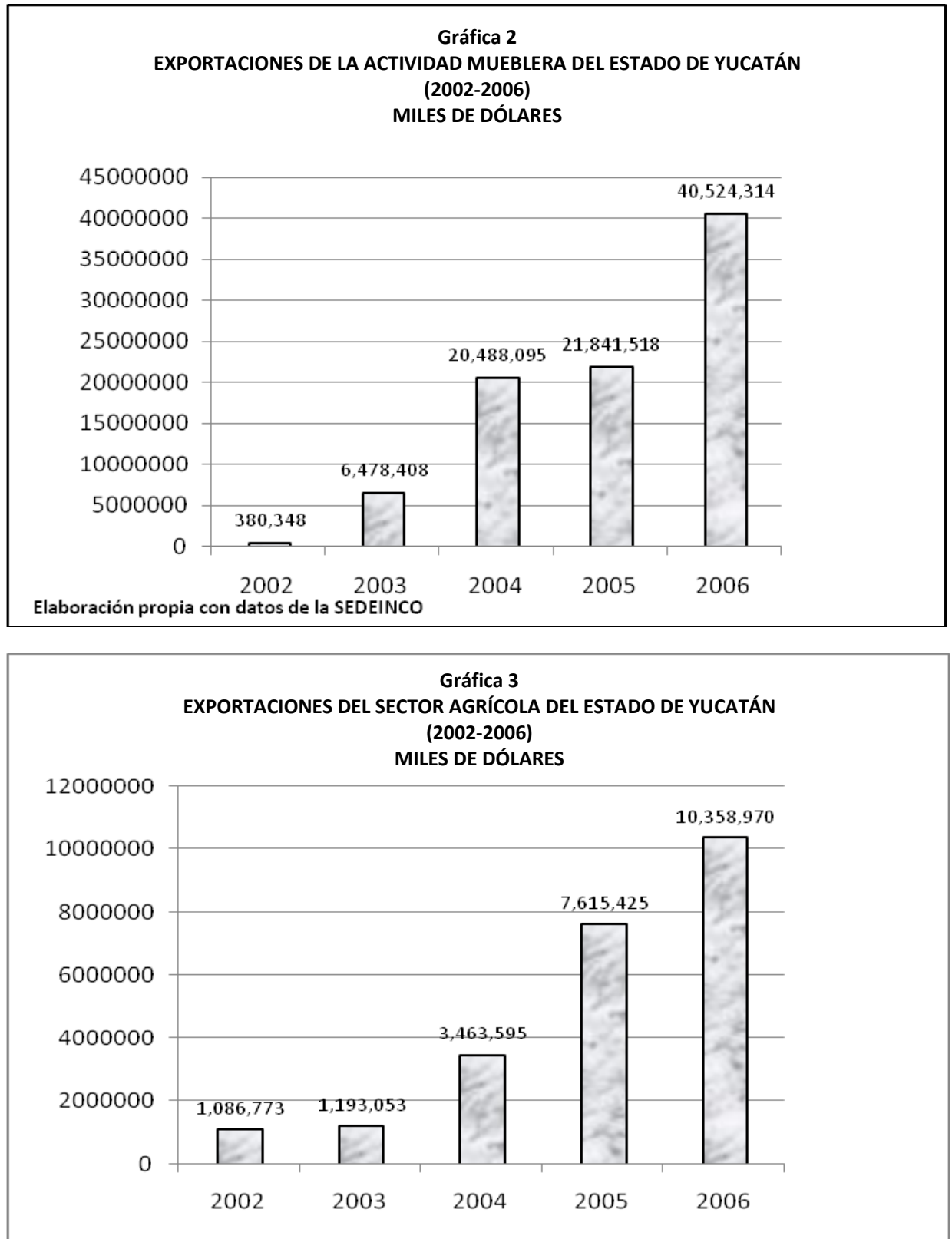
Las instalaciones de un almacén refrigerado en puerto Progreso, han posicionado a Yucatán en el comercio internacional de productos agrícolas, y actualmente productos como el pepino, la toronja, el limón persa, la sandía y el chile habanero utilizan esta área como centro de acopio, consolidación y distribución de sus productos, llegando a los mercados internacionales de Francia, Bélgica, Alemania, Holanda, Inglaterra, Polonia, Italia, Estados Unidos y Canadá.

Subsector máquinas y equipos industriales. Máquina y equipos industriales es otro de los subsectores más dinámicos en las exportaciones de productos elaborados en el estado y en la generación de divisas para el mismo, esto lo ilustra la gráfica 5 a continuación, en donde como se puede observar, el comportamiento del valor de sus exportaciones en lo general se caracterizó por una tendencia creciente del año 2002 al 2006, registrando un crecimiento total en el periodo de 104\%, el cuarto más dinámico.

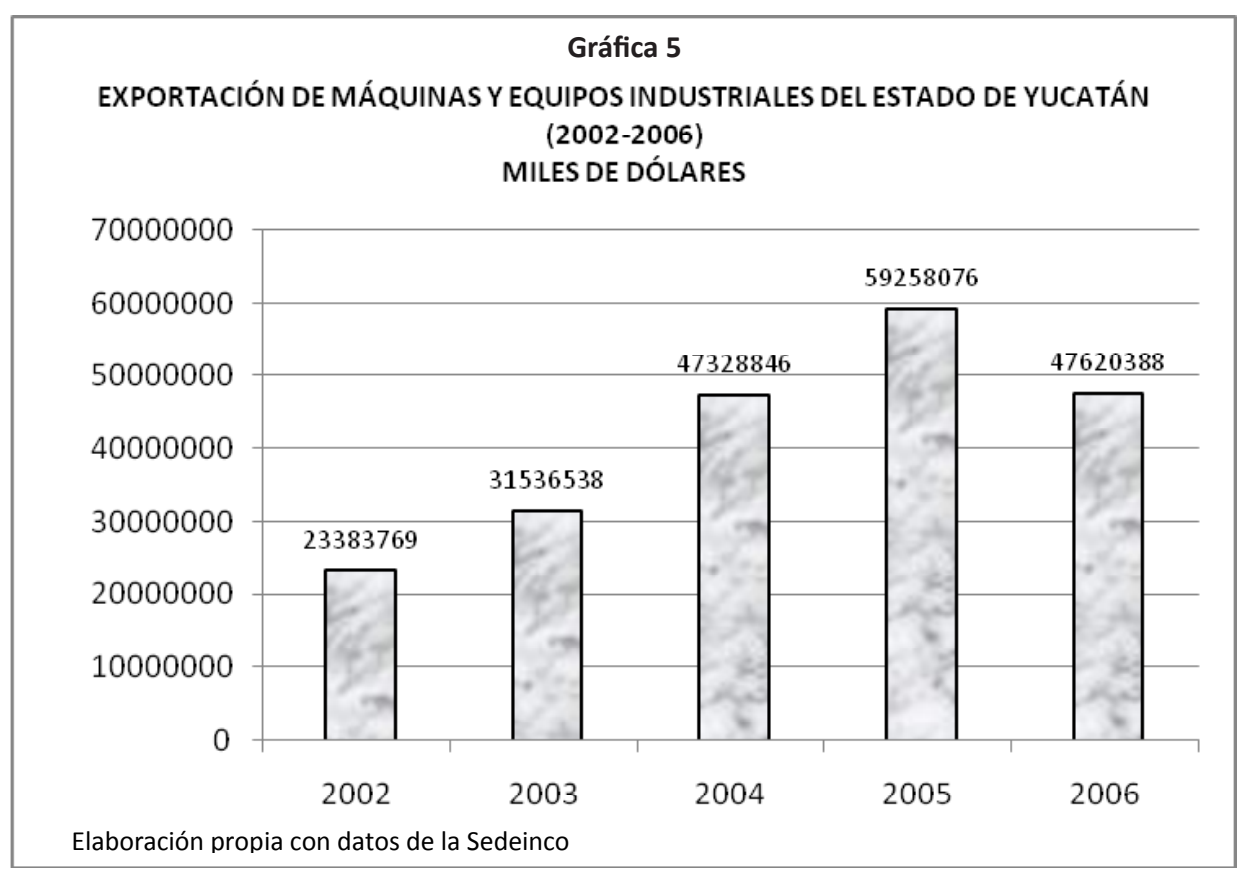


Entre los productos que comprende este subsector se encuentran: aire acondicionado para vehículos, refrigeradores, congeladoras, máquinas de coser, máquinas y aparatos para producción de frío no eléctricos. En cuanto a los países a donde principalmente se envían estos equipos son: Estados Unidos, Hong Kong, República Dominicana y Nicaragua.

Subsector pesca. El producto pesquero y acuícola se ha convertido en el más internacionalizado de todos los comercios de productos alimenticios en el mundo. Cifras oficiales de la ONU para la Agricultura y la Alimentación (FAO) indican que el comercio internacional de productos pesqueros ha sobrepasado en los años recientes los 50,000 millones de dólares anuales y que cerca de un tercio de toda la producción pesquera y marisquera mundial está destinada al comercio internacional.

El comportamiento del comercio internacional de la actividad pesquera del estado en lo general se caracterizó por registrar una tendencia creciente del año 2002 al 2006, con excepción de la caída que registró en el año 2003; pasó de registrar un valor total de 59,716, 304 miles de dólares en 2002 a un valor de 84,138,295 miles de dólares en 2006, siendo su porcentaje de crecimiento total de $41 \%$.

El subsector Pesca es otra de las actividades que participan en el mercado internacional con productos yucatecos de importancia (aportó 6.5\% del valor total exportado en 2006 por la entidad). Las principales especies provenientes del mar yucateco comercializadas en el mercado internacional son: el pulpo, las diversas clases de pescado fresco y congelado, la langosta, el cangrejo, los camarones y las almejas, siendo los principales países en donde se comercializan estos productos los Estados Unidos, Italia, España, Japón, Francia, Panamá, Uruguay y Mónaco.

Subsector pecuario. En este subsector los principales productos yucatecos que se comercializan en el mercado internacional son la miel, la carne porcina y los bovinos en pie, y entre los principales países destino de estos productos se encuentran: los Estados Unidos, Alemania, Canadá, Japón, Corea y Suiza.

El comportamiento del valor de las exportaciones de este ramo se caracterizó del 2002 al 2006 por presentar en lo general una tendencia decreciente en su comportamiento, registrando una tasa total de variación 
de $-15.75 \%$. Pasó de registrar un valor total de 49,012,019 miles de dólares en 2002 a registrar uno de 41,288,159 miles de dólares en 2006. No obstante lo anterior, la porcicultura es la actividad que cobra más fuerza dentro de la oferta exportable de este subsector, encontrándose entre los aspectos que contribuyen a esto el nivel de tecnificación e integración de los productores locales (mano de obra calificada y elaboración de cortes especializados) y las oportunidades de negocios recientes con Japón, un fuerte consumidor de carne de cerdo quien también adquiere productos locales como jugo de naranja, carne de pollo y de res,${ }^{12}$ bajo el marco del Tratado de Libre Comercio suscrito por el país con esta nación. Hay que señalar que Yucatán se mantiene como uno de los principales exportadores de carne de cerdo a Japón y Corea ${ }^{13}$ dos de los mercados más exigentes en el mundo, y desde hace algunos años exporta anualmente unas 600 toneladas aproximadamente de cortes finos de cerdo a estos dos países.

Subsector otras industrias. Entre los principales productos que son exportados por este subsector se encuentran: cajas de cartón, bolsas y bolsitas de papel, cartón, cartón corrugado, libros de registro, libros de contabilidad, talonarios, agendas, bloques de papel, cuadernos, manufacturas de cera, parafina, estearina, resinas naturales, materias vegetales o minerales, entre otros. Su principal mercado destino son los países centroamericanos.

La actuación del valor de las exportaciones de este subsector queda expresada en la siguiente gráfica, y como se puede observar los ingresos que aportó se caracterizaron por ser en lo general crecientes, aunque con altibajos, registrando un crecimiento total en el periodo 2000-2006 de 44.27\%. Pasó de registrar un valor total de 27,682, 563 miles de dólares en 2002 a un valor de 39,937,511 miles de dólares en 2006.

Subsector médico-quirúrgico, óptico y fotografía. Mérida, la capital de Yucatán es considerada el punto médico más importante del sureste de México lo que crea una enorme puerta de oportunidades para la prestación de estos servicios y la manufactura de los productos que requiere. Entre los productos manufacturados que comprende este subsector se

\footnotetext{
${ }^{12}$ Adicionalmente, se exportan a Japón productos como pulpo, camarón, limón y papaya sin pagar aranceles.

${ }^{13}$ Sonora es el otro estado mexicano que exporta carne de cerdo a Asia.
} 
encuentran los artículos y aparatos de ortopedia, instrumentos y aparatos de odontología, aparatos para pruebas visuales, anteojos, instrumentos de dibujo, instrumentos de medida, calibradores, velocímetro y tacómetros.

La representación de este subsector en Yucatán incluye a la empresa Ormex, SA de CV, una división de Ormco Corporation, quien es uno de los productores más grandes de aparatos de ortodoncia en el mundo. Ormex, además, es la primera maquiladora instalada en Yucatán, en 1982, y también fabrica acero inoxidable tradicional y lo último en tecnología en níquel y titanio para registros de endodoncia para Sybron-Endo, división de Ormco. La otra empresa importante en este ramo es Tristar Dental Laboratory, corporación multinacional de Houston, cuya subsidiaria en Yucatán es Reytek, la cual fabrica coronas, puentes dentales e incrustaciones laminadas. El 50\% de la producción de esta empresa se vende en el mercado nacional y 50\% se exporta a los Estados Unidos.

El comportamiento del valor de las exportaciones de este subsector mostró una tendencia creciente a lo largo del periodo y su crecimiento total en el mismo fue de sólo $22 \%$. Paso de registrar un valor total de 22,429,128 miles de dólares en 2002 a registrar uno de 27,402,576 miles de dólares en 2006.

Subsector alimentos procesados y bebidas. El giro agroindustrial constituye uno de los principales a desarrollar en el estado de Yucatán en el área agrícola, por su alto impacto en el empleo en el sector rural y por la posibilidad de surtir al enorme mercado de Estados Unidos respecto de productos agrícolas con valor agregado, entre éstos el maracuyá, la piña, la sábila, la pitahaya, la papaya maradol, el mamey, el tomate, los cítricos y otras frutas exóticas; todos ellos, adicionalmente, de fuerte demanda en los mercados internacionales.

Entre los productos que elabora y fabrica este subsector para su venta en el exterior, se ubican las grasas y el aceite animal o vegetal, salsas preparadas, condimentos y sazonadores, agua, agua mineral y la gasificada, jugo de naranja, jugo de frutas o de hortalizas, aceite de palma o aceite en bruto.

En este contexto, el valor total de las exportaciones del subsector de alimentos procesados y bebidas del estado se caracterizó por una tendencia en lo general creciente, registrando en el periodo 2000-2006 un crecimiento total de $19.10 \%$. Pasó de registrar un valor total de 12,415,076 
miles de dólares en 2002 a registrar uno de 14, 786,805 miles de dólares en 2006. El principal destino de estos productos es Estados Unidos de Norteamérica, donde se envía el 80\% aproximadamente del total, en tanto el restante de la producción se divide en países como Alemania, España, Cuba e Italia; en Europa entre los productos que se exportan por este medio destacan: pescado y mariscos, miel, aceite y grasas de origen animal, entre otros.

Subsector plásticos y sus manufacturas. El subsector plástico y sus manufacturas comprende los siguientes productos: artículos para el transporte o envasado, de plástico, tapas, tapones, sacos (bolsas), botellas, depósitos, cisternas, desechos, desperdicios y recortes de plástico y policarbonatos. En la entidad se encuentran instaladas empresas que exportan una gran diversidad de estos productos. Un ejemplo lo constituye la empresa Cemix que exporta tinacos, preferentemente con destino a los países de Centroamérica.

El comportamiento del valor de las exportaciones de este subsector en lo general también mostró un comportamiento creciente, aunque su crecimiento total en el periodo 2000-2006 fue de sólo el 13.07\%. Pasó de registrar un valor total de 10,993,219 miles de dólares en 2002 a registrar uno de 12, 429,963 miles de dólares en 2006.

Subsector minerales no metálicos. Entre los productos que comprende este ramo se encuentran: el polvo de piedra natural, la piedra de talla o de construcción trabajada, la sal de mesa y desnaturalizada, ladrillos, placa, baldosas, grava de piedra pómez, piedra pómez en bruto o en trozos irregulares y cemento. El comportamiento del valor de las exportaciones de este subsector se caracterizó por ser creciente en el periodo 2000-2006, registrando un crecimiento total de $15.91 \%$. Pasó de registrar un valor total de 5,146,158 miles de dólares en 2002 a registrar uno de 8,229,074 miles de dólares en 2006.

El movimiento de carga de estos productos se realiza en el puerto de Progreso, ocupando, en términos de volumen, los principales lugares: en primer término la sal, seguido de las manufacturas de piedra de cantera, los ladrillos de piedra, el cemento y la grava de piedra. Los principales mercados destino de estos productos son Estados Unidos de Norteamérica, Alemania, España, Italia y Cuba. 


\section{Países receptores del Comercio Exterior del estado de Yucatán}

Los principales países en los que ingresaron los productos de Yucatán comercializados en el mercado internacional de 2002 a 2006, quedó conformado de la siguiente manera (en términos de porcentaje de participación):

En el año 2002 Estados Unidos de Norteamérica fue el país más importante con el 81.2\% del total exportado; le siguieron en este orden, aunque con una mucho menor tasa de participación, Honduras con 6.7\%, Alemania con 2.4\%, la Isla Caimán con 2.1\%, Italia con 1.4\%, República de China con un $1.2 \%$ y Hong Kong con $0.7 \%$.

Para el año siguiente, 2003, los principales países hacia donde se enviaron los productos de Yucatán fueron: nuevamente Estados Unidos en primer lugar con $82.9 \%$, seguido de Honduras con 6.2\%, la Isla Caimán con $2.8 \%$, Alemania con $2.0 \%$, Italia con $1.2 \%$, Hong Kong con $1.0 \%$ y Canadá con $0.7 \%$ (nuevo mercado de los productos del estado en ese entonces).

En 2004 de nueva cuenta se expande la cobertura de las exportaciones estatales y surgen dos nuevos mercados, el de Irlanda (participación de 1.8\%) y el de Macao (participación de 1.6\%). Se mantiene en ese año la distribución de los mercados de exportación, con Estados Unidos a la cabeza con $80.4 \%$ del valor de las ventas al exterior, Honduras es segundo con 3.8\% (cabe mencionar que las ventas a ese país cayeron de forma muy acentuada en este año), Canadá en tercero con el 1.2\%, Isla Caimán con 1.8\% e Italia con $1.0 \%$.

Para el año 2005, el principal destino de los productos locales siguió siendo Estados Unidos, que representó $78.6 \%$ de la compra de los productos del estado, seguido de Irlanda con 5.5\%, Macao con 5.3\%, Isla Caimán con 2.3\% y Canadá con 1.2\%. Los otros dos países que presentaron participación, aunque marginal, fueron: Alemania con $0.8 \%$ y Cuba con $0.7 \%$.

En el último año considerado, 2006, la composición de la distribución de los mercados destino de los productos exportados por el estado se mantuvo, siendo Estados Unidos de Norteamérica el mercado principal en el envío de las ventas estatales, con 79\%, seguido de Irlanda con $6 \%$, Macao con $4 \%$, Isla Caimán con $2 \%$, Canadá con $2 \%$ e Italia con $1 \%$. También registra participación, aunque con una muy baja importancia relativa, Honduras con $0.2 \%$, y como se puede observar, este país, de ser uno de los principales mercados de los productos yucatecos en el pasado, 
actualmente ha disminuido de manera considerable sus adquisiciones de los productos locales y otros países $5.8 \%$.

Para concluir, en la gráfica 6 que se muestra a continuación, se indican los porcentajes de participación por subsector en el total de los productos exportados por el estado de Yucatán durante el periodo 2002 a 2006. Se señalan los principales subsectores en los que se ha concentrado la exportación estatal; previamente destacados, fueron el textil y de la confección, con una participación de $51 \%$ y el de la joyería con $26 \%$ del total. Le siguen en importancia, aunque con una participación relativa mucho menor, los productos de la pesca con 6\%; el pecuario y el de máquinas y equipos industriales con $4 \%$ cada uno respectivamente, las otras industrias con $3 \%$; y el de los muebles, el de equipo médico, quirúrgico-óptico y fotografía con $2 \%$ cada uno respectivamente.

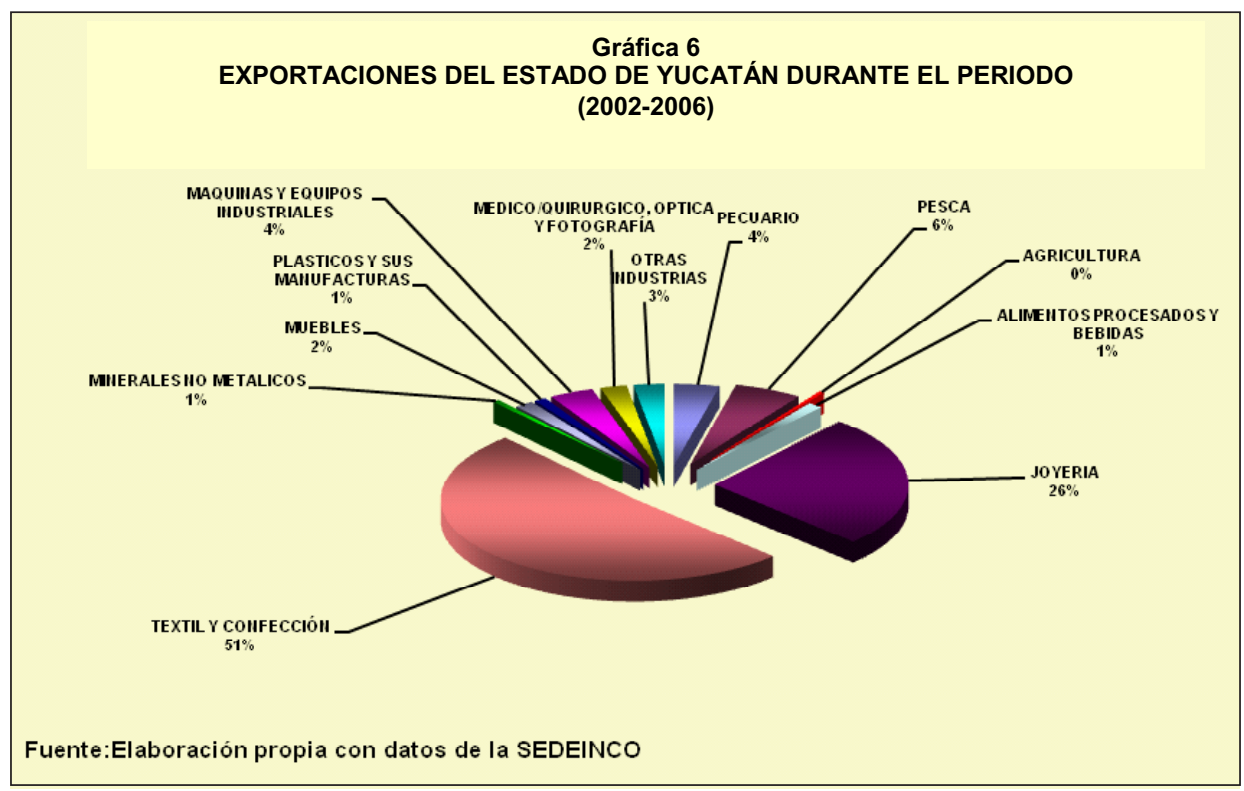

\section{Conclusiones}

No cabe duda que el comercio mundial es un elemento indispensable para lograr el desarrollo de los países. Hoy además no existen países completamente autosuficientes $\mathrm{y}$, por lo tanto, este es un proceso económico del cual no puede prescindir el mundo contemporáneo. 
En Yucatán se puede decir que se ha tenido un desarrollo paulatino en materia de comercio exterior, no obstante que el Estado al paso de los años se ha venido consolidando cada vez más como principal proveedor de actividades comerciales y de servicios, por la falta de producción de básicos en el mismo.

En el contexto histórico y geográfico la actividad comercial de Yucatán ha sido importante, tanto interna como externamente. Las relaciones comerciales de la entidad se han venido realizando desde la época prehispánica, con países de Centroamérica y del Altiplano mexicano en ese entonces, y a partir de los siglos XIX y XX, Yucatán viene exportando productos prácticamente hacia todas partes del mundo (Europa, Asia, etcétera).

Es a partir de la segunda mitad del siglo XIX cuando en la entidad comienza el henequén a ocupar un lugar preponderante entre las exportaciones del estado dando como consecuencia una mayor atención a sus flujos comerciales, no obstante lo anterior, esto no le restó importancia a los demás productos locales que se comercializaban en el exterior.

Sin embargo, en las décadas de los 70 y 80 del siglo $\mathrm{XX}$, ante la crisis que sufrió la industria henequenera, que repercutió negativamente en la economía estatal, se da la decadencia exportadora de este producto. Ante ello surgen otros productos de la región que se empiezan a comercializar en forma importante en el exterior, entre los que destacan la semilla de calabaza, el jugo de naranja, la sal, la miel, los pescados y mariscos, la ropa, las manufacturas de madera, entre otros.

El proceso de transformación y de cambios acontecidos en la sociedad (actualmente la globalización y los bloques económicos), en los cuales el país se encuentra inmerso y del que Yucatán no está exento, han dado lugar a nuevas formas de realizar el comercio exterior entre países. En este contexto, la actividad comercial del estado con el mercado internacional se ha reducido hoy en día a la realización de procesos de transformación y maquila de productos que son enviados de retorno a su país de origen o a la central de la empresa, ubicada en otra parte del planeta. Por lo tanto, la actividad del comercio exterior de Yucatán expresa una estrecha relación de dependencia con respecto de las importaciones de estas empresas, sobre todo de las provenientes de la inversión extranjera directa de los Estados Unidos de Norteamérica en la entidad. 
No obstante lo anterior, es importante también destacar que el estrechamiento de las relaciones del estado con el exterior ha influido para que la demanda de productos elaborados en Yucatán sea cada vez mayor en la actualidad, lo que ha dado como consecuencia que se produzcan avances importantes en el sector industrial local (agropecuario y textil principalmente), al operarse una diversificación en los productos que se elaboran en esta rama económica en la entidad.

Por otra parte, la ubicación geográfica de Yucatán, situada en el centro del Golfo de México, le ha convertido en un punto comercial importante entre Norte, Centro y América del Sur, destacándolo como una magnifica plataforma para el comercio internacional. Papel importante juegan en esto el puerto de Progreso, eficaz promotor del desarrollo del sureste mexicano en el mercado internacional, al facilitar el enlace entre el transporte marítimo y terrestre en el tráfico de mercancías; así como también el Aeropuerto internacional de la ciudad de Mérida, el cual responde a los principios de rapidez y eficiencia en la entrega de mercancías y productos comerciales, y a la variedad de opciones en cuanto a costo, servicio y horarios para transporte, que el actual mundo globalizado exige.

La economía del estado de Yucatán ha presentado una evolución y un desarrollo importantes desde hace aproximadamente 30 años y es necesario que este proceso continúe de manera gradual y sostenida. Parte importante en el logro de lo anterior lo ha sido el crecimiento del comercio exterior, el cual ha revitalizado buena parte de la economía yucateca, generando importantes flujos de divisas, que en la actualidad proceden principalmente de Estados Unidos de Norteamérica y de Europa (Irlanda e Italia de los países más importantes), consecuencia del nivel de calidad de los productos locales.

Reflejo de lo anterior es que en el periodo 2002-2006 el valor total de las exportaciones de Yucatán mostró en lo general una tendencia creciente en su comportamiento, denotando sus incrementos más significativos a partir del año 2003. Por lo tanto, la diversificación industrial, la infraestructura disponible en los puntos de salida de productos al exterior, así como las acciones de los gobiernos federal y estatal para impulsar la oferta exportadora local, han permitido que esta actividad evolucione arrojando cifras crecientes y positivas en el estado. Un indicador al respecto lo constituye la participación en el valor total de las exportaciones de la entidad 
de los diferentes subsectores económicos exportadores que la integran, en donde los principales en que se ha concentrado están en el periodo 2002-2006 y han sido el textil y de la confección y el de joyería, con menor participación relativa el de pesca, el pecuario y el de máquinas y equipos industriales.

En contraste, el subsector más dinámico en materia de exportación en el periodo de referencia fue el de muebles (tendencia creciente y una tasa de crecimiento total de 10,554.53\%), siguiéndole en importancia, aunque con una tasa de crecimiento total mucho menos dinámica, los subsectores agrícola, el joyero y el de maquinarias y equipo industrial, el textil y de la confección, que se caracterizó por presentar una dinámica opuesta.

Es de importancia señalar que la clasificación actual establecida para los diversos subsectores económicos de Yucatán dedicados al comercio exterior, ubica diversos productos netamente yucatecos que se han convertido ya en tradicionales y que por años se han comercializado en el mercado internacional; entre éstos destacan la miel industrializada, la sal de mesa, los pescados frescos y congelados, el jugo de naranja, la carne de cerdo, los bovinos en pie, los productos pétreos, el cemento, las cuerdas de henequén, entre otros; es de importancia impulsar su desarrollo si se quiere ampliar la presencia del estado en el comercio mundial.

Por otro lado, aunque el valor de las exportaciones hacia Estados Unidos de Norteamérica, principal destino de los productos exportados por la entidad, tuvo un importante crecimiento entre 2002 y 2006, su peso dentro del total disminuyó, pasando de representar $81 \%$ del total de las exportaciones del estado en el año 2002, a sólo $78 \%$ en el 2006, lo cual se puede considerar como un reflejo de la mayor diversificación que se está dando en las ventas estatales al exterior, al aprovechar los beneficios de los tratados comerciales que tiene México con otros países (Japón es un ejemplo importante al respecto para Yucatán).

Por último, aunque las cifras destacadas muestran que las ventas al exterior del estado están muy concentradas en pocos países (Estados Unidos de Norteamérica, Irlanda, Macao, Isla Caimán, Canadá e Italia), es de importancia denotar la existencia de un foco de oportunidad constituido por las empresas que han logrado incursionar, aunque en pequeña escala (el caso del chile habanero), a países muy alejados de la entidad, tanto geográfica como culturalmente, entre éstos, Hungría, Corea del Sur, Malasia y Taiwán. 


\section{Bibliografía}

Acevedo Azarcoya, Gilberto, (1993). Breve reseña del comercio exterior de Yucatán. Ensayo, Facultad de Economía de la UADY.

Castañeda Navarrete, Jennifer, (2007). Cambio institucional y desarrollo económico en Yucatán 1984-2004. Tesis. Fac. de Economía de la UADY.

Coba López, Fernando, (1977). Estructura comercial de Yucatán. Tesis. Fac. de Economía de la UDY.

Calderón Hinojoza, Felipe, (2007). Plan Nacional de Desarrollo de México, 2007-2012. México.

Casanova Coronado, Orlando, (1999). El comercio exterior de Yucatán. Ensayo, Facultad de Economía de la UADY.

Eastmond, Amarella, (1999). Agricultura y ganadería. Atlas del proceso territorial de Yucatán. FAUDY pp. 77-88.

Escalante Perera, Raúl, (1988). Algunos aspectos del comercio exterior de Yucatán 1980-1986. Tesis. Fac. de Economía de la UDY.

García de Fuentes, Ana y Morales, Josefina, (2000). “Dinámica Regional de Yucatán 1980-2000”. Boletín del Instituto de Geografía, UNAM. Núm. 42.

Hernández, Sampieri, R. et al. (2003). Metodología de la investigación. Editorial McGraw-Hill, México, D.F.

Mena Bates, Andrés, (1985). El comercio y su influencia en la economía del estado de Yucatán. Tesis. Fac. de Economía de la UDY.

Mercier, Delphine, (2005). "La industria maquiladora de exportación mexicana hace 40 años”. Revista Galega de Economía. Vol. 14. Núm. pp. 1-2. 
Pasos Pérez, Teresa de Jesús y Can Castillo, Nidia Mercedes, (1979). Contribución del comercio exterior al desarrollo de la economía yucateca 1970-1977. Tesis. Fac. de Economía de la UDY.

Patrón Laviada, Patricio, (2007). Sexto Informe de Gobierno del Estado de Yucatán 2007.

Parkin, Michael y Esquivel, Gerardo, (2001). Microeconomía; versión para Latinoamérica. Quinta edición. Pearson Education. México.

Paz Sánchez, Fernando, (2008). "La globalización económica y la industria del vestido”. Revista de Macroeconomía, 1 de marzo, Num. 175.

Sedeinco. (2006). Revista Pulso Económico. Gobierno del Estado de Yucatán. Núm. 11. julio-septiembre.

Sedeinco. (2006). Revista Pulso Económico. Gobierno del Estado de Yucatán. Núm. 12. octubre-diciembre.

Vela Sosa, Raúl. (2005). "Comercio Internacional. Notas sobre el desafío del sector externo yucateco". Revista Contexto Profesional. Año 1. Núm. 4. agosto- septiembre, Confederación de Profesionistas de la Península.

\section{Páginas de Internet:}

www.sagarpa.gob.mx

w w w.s ed in c oy u c a t a n.gob.mx/esp/noticia s / verarticulo,php?Idarticuloo139

www.siap.sagarpa.gob.mx

www.puertosyucatan.com/cgi_bin 